\title{
Trends of inorganic and organic aerosols and precursor gases in Europe: insights from the EURODELTA multi-model experiment over the 1990-2010 period
}

Giancarlo Ciarelli $^{1,2, a}$, Mark R. Theobald ${ }^{3}$, Marta G. Vivanco ${ }^{3}$, Matthias Beekmann ${ }^{1}$, Wenche Aas ${ }^{4}$, Camilla Andersson ${ }^{5}$, Robert Bergström ${ }^{5,6}$, Astrid Manders-Groot ${ }^{7}$, Florian Couvidat ${ }^{2}$, Mihaela Mircea $^{8}$, Svetlana Tsyro ${ }^{9}$, Hilde Fagerli ${ }^{9}$, Kathleen Mar ${ }^{10}$, Valentin Raffort ${ }^{11}$, Yelva Roustan ${ }^{11}$, Maria-Teresa Pay $^{12}$, Martijn Schaap ${ }^{7}$, Richard Kranenburg ${ }^{7}$, Mario Adani ${ }^{8}$, Gino Briganti ${ }^{8}$, Andrea Cappelletti ${ }^{8}$, Massimo D'Isidoro ${ }^{8}$, Cornelis Cuvelier $^{13}$, Arineh Cholakian ${ }^{1,2}$, Bertrand Bessagnet ${ }^{2, b}$, Peter Wind ${ }^{9,14}$, and Augustin Colette ${ }^{2}$

${ }^{1}$ Laboratoire Interuniversitaire des Systèmes Atmosphériques (LISA), UMR CNRS 7583, Université Paris-Est-Créteil, Université de Paris, Institut Pierre Simon Laplace, Créteil, France

${ }^{2}$ National Institute for Industrial Environment and Risks (INERIS), Parc Technologique ALATA, 60550 Verneuil-en-Halatte, France

${ }^{3}$ CIEMAT, Research Centre for Energy, Environment and Technology, Madrid, Spain

${ }^{4}$ Norwegian Institute for Air Research (NILU), P.O. Box 100, 2027 Kjeller, Norway

${ }^{5}$ Swedish Meteorological and Hydrological Institute, 60176 Norrköping, Sweden

${ }^{6}$ Department of Space, Earth and Environment, Chalmers University of Technology, 41296 Gothenburg, Sweden

${ }^{7}$ Netherlands Organisation for applied scientific research (TNO), P.O. Box 80015, 3508 TA Utrecht, the Netherlands

${ }^{8}$ Italian National Agency for New Technologies, Energy and Sustainable Economic Development (ENEA),

Via Martiri di Monte Sole 4, 40129 Bologna, Italy

${ }^{9}$ Climate Modelling and Air Pollution Division, Research and Development Department, Norwegian Meteorological Institute (MET Norway), Blindern, 0313 Oslo, Norway

${ }^{10}$ Institute for Advanced Sustainability Studies (IASS), Potsdam, Germany

${ }^{11}$ CEREA, Joint Laboratory Ecole des Ponts ParisTech - EDF R\&D, Champs-sur-Marne, France

${ }^{12}$ Barcelona Supercomputing Center, Centro Nacional de Supercomputación, Jordi Girona, 29, 08034 Barcelona, Spain

${ }^{13}$ ex European Commission - JRC, Ispra, Italy

${ }^{14}$ Faculty of Science and Technology, University of Troms $\varnothing$, Troms $\varnothing$, Norway

anow at: Department of Chemical Engineering, Carnegie Mellon University, Pittsburgh, PA, USA

${ }^{b}$ now at: Hangzhou Futuris Environmental Technology Co. Ltd, Zhejiang Overseas High-Level Talent Innovation Park, No. 998 WenYi Road, 311121, Hangzhou, Zhejiang, China

Correspondence: Giancarlo Ciarelli (giancarlo.ciarelli@lisa.u-pec.fr)

Received: 19 March 2019 - Discussion started: 3 April 2019

Revised: 11 September 2019 - Accepted: 4 October 2019 - Published: 29 November 2019

\begin{abstract}
In the framework of the EURODELTA-Trends (EDT) modeling experiment, several chemical transport models (CTMs) were applied for the 1990-2010 period to investigate air quality changes in Europe as well as the capability of the models to reproduce observed long-term air quality trends. Five CTMs have provided modeled air quality data for 21 continuous years in Europe using emission scenarios prepared by the International Institute for Applied Sys-
\end{abstract}

tems Analysis/Greenhouse Gas - Air Pollution Interactions and Synergies (IIASA/GAINS) and corresponding year-byyear meteorology derived from ERA-Interim global reanalysis. For this study, long-term observations of particle sulfate $\left(\mathrm{SO}_{4}^{2-}\right)$, total nitrate $\left(\mathrm{TNO}_{3}\right)$, total ammonium $\left(\mathrm{TNH}_{x}\right)$ as well as sulfur dioxide $\left(\mathrm{SO}_{2}\right)$ and nitrogen dioxide $\left(\mathrm{NO}_{2}\right)$ for multiple sites in Europe were used to evaluate the model results. The trend analysis was performed for the full 21 years 
(referred to as PT) but also for two 11-year subperiods: 1990-2000 (referred to as P1) and 2000-2010 (referred to as $\mathrm{P} 2$ ).

The experiment revealed that the models were able to reproduce the faster decline in observed $\mathrm{SO}_{2}$ concentrations during the first decade, i.e., 1990-2000, with a $64 \%-76 \%$ mean relative reduction in $\mathrm{SO}_{2}$ concentrations indicated by the EDT experiment (range of all the models) versus an $82 \%$ mean relative reduction in observed concentrations. During the second decade (P2), the models estimated a mean relative reduction in $\mathrm{SO}_{2}$ concentrations of about $34 \%-54 \%$, which was also in line with that observed (47\%). Comparisons of observed and modeled $\mathrm{NO}_{2}$ trends revealed a mean relative decrease of $25 \%$ and between $19 \%$ and $23 \%$ (range of all the models) during the P1 period, and $12 \%$ and between $22 \%$ and $26 \%$ (range of all the models) during the P2 period, respectively.

Comparisons of observed and modeled trends in $\mathrm{SO}_{4}^{2-}$ concentrations during the $\mathrm{P} 1$ period indicated that the models were able to reproduce the observed trends at most of the sites, with a $42 \%-54 \%$ mean relative reduction indicated by the EDT experiment (range of all models) versus a $57 \%$ mean relative reduction in observed concentrations and with good performance also during the P2 and PT periods, even though all the models overpredicted the number of statistically significant decreasing trends during the P2 period. Moreover, especially during the P1 period, both modeled and observational data indicated smaller reductions in $\mathrm{SO}_{4}^{2-}$ concentrations compared with their gas-phase precursor (i.e., $\mathrm{SO}_{2}$ ), which could be mainly attributed to increased oxidant levels and $\mathrm{pH}$-dependent cloud chemistry.

An analysis of the trends in $\mathrm{TNO}_{3}$ concentrations indicated a $28 \%-39 \%$ and $29 \%$ mean relative reduction in $\mathrm{TNO}_{3}$ concentrations for the full period for model data (range of all the models) and observations, respectively. Further analysis of the trends in modeled $\mathrm{HNO}_{3}$ and particle nitrate $\left(\mathrm{NO}_{3}^{-}\right)$concentrations revealed that the relative reduction in $\mathrm{HNO}_{3}$ was larger than that for $\mathrm{NO}_{3}^{-}$during the $\mathrm{P} 1$ period, which was mainly attributed to an increased availability of "free ammonia". By contrast, trends in modeled $\mathrm{HNO}_{3}$ and $\mathrm{NO}_{3}^{-}$concentrations were more comparable during the $\mathrm{P} 2$ period. Also, trends of $\mathrm{TNH}_{x}$ concentrations were, in general, underpredicted by all models, with worse performance for the P1 period than for P2.

Trends in modeled anthropogenic and biogenic secondary organic aerosol (ASOA and BSOA) concentrations together with the trends in available emissions of biogenic volatile organic compounds (BVOCs) were also investigated. A strong decrease in ASOA was indicated by all the models, following the reduction in anthropogenic non-methane VOC (NMVOC) precursors. Biogenic emission data provided by the modeling teams indicated a few areas with statistically significant increase in isoprene emissions and monoterpene emissions during the 1990-2010 period over Fennoscandia and eastern European regions (i.e., around 14\%-27\%), which was mainly attributed to the increase of surface temperature. However, the modeled BSOA concentrations did not linearly follow the increase in biogenic emissions. Finally, a comprehensive evaluation against positive matrix factorization (PMF) data, available during the second period (P2) at various European sites, revealed a systematic underestimation of the modeled SOA fractions of a factor of 3 to 11 , on average, most likely because of missing SOA precursors and formation pathways, with reduced biases for the models that accounted for chemical aging of semi-volatile SOA components in the atmosphere.

\section{Introduction}

Particulate matter (PM) is one of the greatest environmental concerns, affecting climate and visibility, and having deleterious effects on human health (Cohen et al., 2017; Pope and Dockery, 2006; WHO, 2013). Although particulate matter can be directly emitted from different sources, e.g., power plants, industry and transport, PM with an aerodynamic diameter below $2.5 \mu \mathrm{m}\left(\mathrm{PM}_{2.5}\right)$ is mainly of secondary origin (Crippa et al., 2014), i.e., formed in the atmosphere after various reactions involving gas-phase precursors such as nitrogen oxide $\left(\mathrm{NO}_{2}\right)$, sulfur dioxide $\left(\mathrm{SO}_{2}\right)$, ammonia $\left(\mathrm{NH}_{3}\right)$, volatile organic compounds (VOCs) and several oxidants (e.g., $\mathrm{OH}, \mathrm{O}_{3}$ and $\mathrm{NO}_{3}$ ). Particles in this size range can penetrate deeply into the respiratory system leading to respiratory and cardiovascular problems. The formation mechanisms leading to secondary aerosols, especially the organic fraction, are complex, non-linear and still not fully understood (Bian et al., 2017; Lachatre et al., 2019; Tsigaridis et al., 2014).

Emissions of $\mathrm{SO}_{2}$ and $\mathrm{NO}_{2}$ have largely declined in $\mathrm{Eu}-$ rope over the recent decades (Fagerli and Aas, 2008; Tørseth et al., 2012; UNECE LRTAP, 2016). For $\mathrm{SO}_{2}$ and $\mathrm{NO}_{2}$, emissions were reported to have declined by about $65 \%$ and $31 \%$, respectively, between 1990 and 2009, whereas emissions of $\mathrm{NH}_{3}$ were reported to have declined by about $29 \%$, although the emission changes exhibit high spatial variability within the European domain (Tørseth et al., 2012). $\mathrm{NH}_{3}$, which is emitted mainly from agricultural activities, is one of the key chemical species involved in the formation of secondary inorganic aerosol. It is the most important base in the atmosphere (Seinfeld and Pandis, 2012) and can react very rapidly with sulfuric acid $\left(\mathrm{H}_{2} \mathrm{SO}_{4}\right)$, which is formed from the oxidation of $\mathrm{SO}_{2}$ with $\mathrm{OH}$ (in the gas phase), $\mathrm{O}_{3}$ and hydrogen peroxide $\left(\mathrm{H}_{2} \mathrm{O}_{2}\right)$ in the aqueous phase, to form ammonium sulfate or ammonium bisulfate (Seinfeld and Pandis, 2012). If enough $\mathrm{NH}_{3}$ is available after the neutralization of $\mathrm{H}_{2} \mathrm{SO}_{4}$, it can react with nitric acid $\left(\mathrm{HNO}_{3}\right)$, which is mainly formed from the oxidation of $\mathrm{NO}$ and $\mathrm{NO}_{2}$, to produce the semivolatile ammonium nitrate. Formation of ammonium nitrate usually occurs when the molar concentration of $\mathrm{NH}_{3}+\mathrm{NH}_{4}^{+}$ 
is more than twice the sulfate concentration (i.e., "free ammonia regime") (Tsimpidi et al., 2007).

Past and future trends in the total PM concentration have recently received great attention thanks to the availability of long-term observational datasets and increased computational power available for long-term chemical transport model (CTM) simulations. Tørseth et al. (2012) analyzed long-term air quality trends from the European Monitoring and Evaluation Programme (EMEP) during a period of 40 years. Their study showed a substantial reduction in ambient concentrations of sulfur species of about $70 \%-90 \%$ starting from 1980, well in line with emission reductions, and a reduction of about $23 \%$ in $\mathrm{NO}_{2}$ concentrations starting from the beginning of the 1990s. However, available observations of total nitrate $\left(\mathrm{TNO}_{3}=\mathrm{HNO}_{3}(\mathrm{~g})+\mathrm{NO}_{3}^{-}(\mathrm{p})\right)$ showed only a minor reduction (about $8 \%$ ), compared to the larger reductions in $\mathrm{NO}_{2}$. Aksoyoglu et al. (2014) performed an air quality modeling study with the Comprehensive Air Quality with extensions (CAMx) model to evaluate air quality changes due to anthropogenic emission changes in the framework of the revised Gothenburg protocol. They performed air quality simulations for the emission years 1990, 2005 and 2020 with emission scenarios prepared from the International Institute for Applied Systems Analysis/Greenhouse Gas Air Pollution Interactions and Synergies (IIASA/GAINS). Their results indicated that the annual mean $\mathrm{PM}_{2.5}$ concentration in Europe decreased by $20 \%-50 \%$ between 1990 and 2005. Moreover, simulated annual mean $\mathrm{PM}_{2.5}$ concentrations were $30 \%$ lower in 2020 compared with 2005, with larger decreases for eastern European countries (Aksoyoglu et al., 2014). Similarly, Colette et al. (2011) investigated the capability of six regional and global CTMs for simulating air quality changes between 1998 and 2007 with a focus on $\mathrm{NO}_{2}, \mathrm{O}_{3}$ and $\mathrm{PM}_{10}$. Their results indicated that the models could reproduce the trends of primary pollutants, but they had difficulties in reproducing the small observed trends in $\mathrm{O}_{3}$, and the year-to-year variability was underestimated, in general. More recently, Banzhaf et al. (2015) applied the LOTOS-EUROS model for the 1990-2009 period to investigate trends of air quality in Europe. They concluded that the model was able to well reproduce the observed trends in primary and secondary produced pollutants. In addition, they also performed a source apportionment study to evaluate the formation efficiency of secondary inorganic species during the 1990-2009 period. Their results indicated an increase in $\mathrm{SO}_{4}^{2-}$ formation efficiency (between $20 \%$ and $50 \%$ ) as well as for $\mathrm{NO}_{3}^{-}$(up to $20 \%$ ) compared with 1990.

Organic aerosol (OA) is often a major fraction of $\mathrm{PM}_{2.5}$. $\mathrm{OA}$ is a complex mixture of thousands of organic compounds with different chemical and physical properties and volatilities (semi-volatile to low volatility) (Huang et al., 2014; Jimenez et al., 2009). Numerous measurement campaigns performed in different parts of the world and periods of the year have revealed that only a minor fraction of the observed total OA mass is directly emitted as primary organic aerosol (POA). A more abundant component, referred to as secondary organic aerosol (SOA), was found to often dominate the composition of OA especially in rural areas (Crippa et al., 2014).

The formation of SOA in the atmosphere is mainly initiated by the oxidation of gas-phase organic compounds in different ranges of saturation concentrations, usually referred to as low-volatility, semi-volatile, intermediate-volatility and high-volatility ranges (Donahue et al., 2012, 2011). Some of the resulting gas-phase oxidation products will acquire lower saturation concentration due to the addition of oxygencontaining functional groups and will eventually condense on pre-existing organic particles leading to formation of SOA (depending on temperature and OA concentrations). On the other hand, other organic compounds will obtain lower molecular weight and will fall into higher saturation concentration ranges through fragmentation, and they will likely reside in the gas phase.

A recent model intercomparison exercise, AeroCom (Tsigaridis et al., 2014), investigated the performance of 31 global models with respect to OA for the year 2006, revealing large differences between models in terms of SOA formation, mainly because of the assumptions made in the SOA scheme used (e.g., chemical aging, multiphase chemistry and semi-volatile SOA assumptions). In addition, comparison with several observational datasets revealed that even though the models were able to simulate the secondary nature of OA, they tended to largely underestimate the observed OA, especially in urban areas (Tsigaridis et al., 2014). In Europe, recent applications of CTMs have started to provide a comprehensive picture of the main sources of OAs as well as their temporal variation throughout the year. Bergström et al. (2012) applied the EMEP Meteorological Synthesizing Centre-West (MSC-W) model with a volatility basis set (VBS) model and tested different assumptions on the volatility distribution of POA as well as on the parameterizations of the aging processes. Their studies revealed an underestimation of OA concentrations, especially during winter periods and in northern European countries, most likely as a result of uncertainties in the emissions from the residential sector (mainly wood burning emissions). Summertime OA levels, on the other hand, were highly influenced by biogenic SOA precursors (isoprene and terpene), as also confirmed by more recent studies (Cholakian et al., 2018; Chrit et al., 2017; Ciarelli et al., 2016).

In this study, we investigate the trends in secondary inorganic aerosol (SIA) and SOA in Europe during the 19902010 period calculated by five CTMs that participated in the EURODELTA-Trends exercise (Colette et al., 2017). The novel multi-model EURODELTA-Trends (EDT) exercise (launched within the Task Force on Measurement and Modelling of the EMEP program supporting the Convention on Long Range Transboundary Air pollution (CLRTAP)) provided 21 years of continuous particulate matter components and their gas-phase precursor concentrations over $\mathrm{Eu}-$ 
EURODELTA-trends domain and PRUDENCE zones

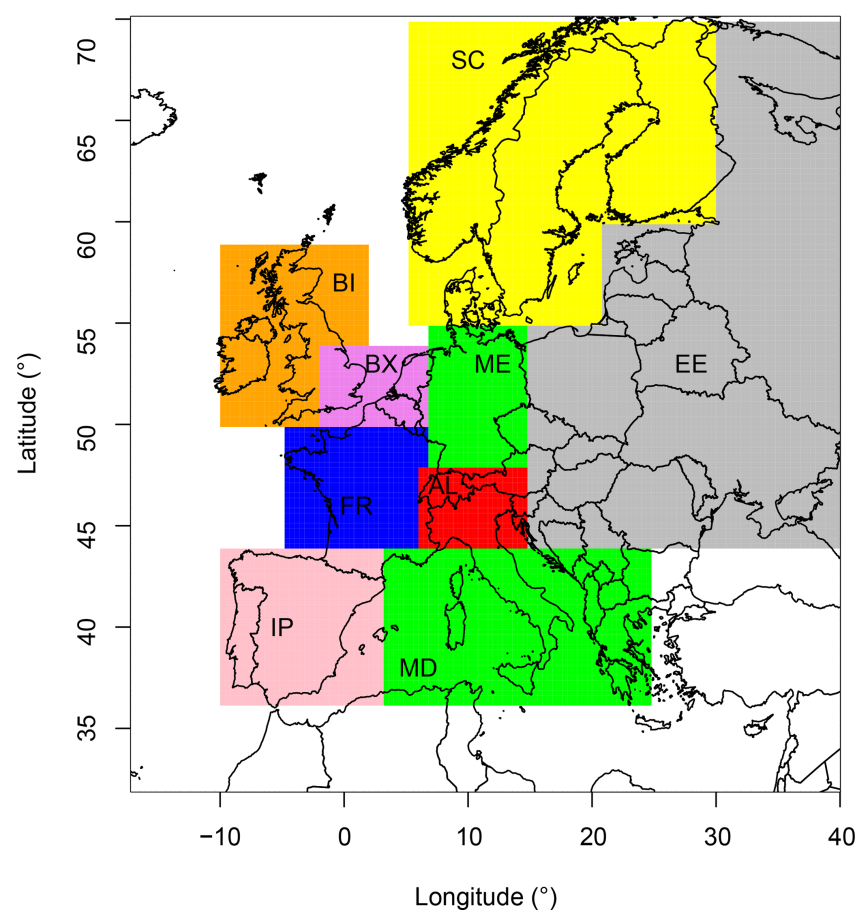

Figure 1. The extension of the EURODELTA-Trends domain as well as that of the subregions adapted from the Prediction of Regional scenarios and Uncertainties for Defining EuropeaN Climate change risks and Effects (PRUDENCE) zones. From south to north: Mediterranean regions (MD), Iberian Peninsula (IP), France (FR), Alps (AL), mid-Europe (ME), eastern Europe (EE), Benelux regions (BX), British Isles (BI) and Fennoscandia (SC).

rope from the year 1990 and with "real" year-to-year meteorological input data. It provides a base for validating the performance of multiple models over an extended period (i.e., 1990-2010) and for assessing the variation of various chemical species not routinely measured in Europe.

The paper is organized as follows. Section 2 provides a general overview of the EURODELTA-Trends experiment, with a description of the models participating in the exercise and the input data used to perform the experiment. The observational data are described in Sect. 2, along with information regarding the quality-control criteria. Results and discussions are presented in Sect. 3. The trends in anthropogenic emissions and inorganic species are discussed in Sect. 3.1 and 3.2, respectively. An evaluation of the secondary organic aerosol fraction is presented in Sect. 3.3 (for the 2000-2010 period) together with the trends in biogenic emission and anthropogenic and biogenic SOA concentrations. Finally, conclusions are presented in Sect. 4.

\section{Methods}

\subsection{Overview of the EURODELTA-Trends experiment}

The EURODELTA-Trends experiment builds upon the expertise of the previous EURODELTA phases initiated in 2004 (van Loon et al., 2007). In the latest EURODELTA experiments, i.e., EURODELTA III, the performance of several CTMs was investigated for common air quality pollutants, i.e., $\mathrm{NO}_{2}, \mathrm{O}_{3}, \mathrm{SO}_{2}, \mathrm{PM}_{10}$ and $\mathrm{PM}_{2.5}$, at a European scale for specific periods of the EMEP and European Integrated Project on Aerosol Cloud Climate and Air Quality Interactions (EUCAARI) intensive measurement campaigns (Bessagnet et al., 2016).

The follow-up EURODELTA experiments, referred to as EDT, aim at investigating the changes in air quality in Europe over the 1990-2010 period. In this framework, stateof-the-art CTMs were applied over the European domain (Fig. 1) with common input data (meteorological fields, anthropogenic emissions and boundary conditions). The participating models carried out extensive sensitivity tests that aimed at disentangling the role of different drivers (e.g., meteorology and emissions) on changes in air quality. The complete list of data available, chemical species and sensitivity tests is reported in detail in Colette et al. (2017).

In this study, one tier of simulations was used to investigate the models' capabilities to reproduce gas-phase PM precursors as well as SIA trends over the 1990-2010 period. This tier, referred to as tier 3A, provides 21 years of modeled air quality data in Europe driven with "real" meteorology, observation-based boundary conditions and anthropogenic emission scenarios based on the IIASA/GAINS model. Biogenic emissions were calculated separately by the different modeling teams using their own biogenic model driven by the meteorological data (e.g., temperature and radiation).

\subsection{Description of the participating models}

A total of eight state-of-the-art air quality CTMs delivered their results for the EDT experiments: CHIMERE (Mailler et al., 2017; Menut et al., 2013), CMAQ (Byun and Schere, 2006), EMEP MSC-W (Simpson et al., 2012), LOTOSEUROS (Manders et al., 2017; Schaap et al., 2008), MATCH (Andersson et al., 2015, 2007; Robertson et al., 1999), MINNI (Mircea, 2016), Polyphemus (Mallet et al., 2007; Sartelet et al., 2012) and WRF-Chem (Grell et al., 2005; Mar et al., 2016). Given the large computational demand of the simulations, only five modeling teams were able to deliver 21 years of continuous air-modeled data: CHIMERE, EMEP MSC-W, LOTOS-EUROS, MATCH and MINNI, the results of which are used in this study. Most of the other models provided air quality data for 3 intermediate years: 1990, 2000 and 2010.

The setup for each participating model is reported in Table 1 . The complete list of physical and chemical schemes 
Table 1. Chemical, thermodynamic schemes and biogenic emission models used by the modeling teams in the EURODELTA-Trends experiment.

\begin{tabular}{|c|c|c|c|c|c|}
\hline Model & $\begin{array}{l}\text { Gas-phase } \\
\text { chemistry }\end{array}$ & SIA module & SOA module & VBS for aerosol & Biogenic model \\
\hline $\begin{array}{l}\text { CHIMERE (model } \\
\text { version } 2017 \beta \\
\text { v1.0) }\end{array}$ & $\begin{array}{l}\text { MELCHIOR2 } \\
\text { (Derognat et al., } \\
\text { 2003) }\end{array}$ & $\begin{array}{l}\text { ISORROPIA v2.1 } \\
\text { (Nenes et al., 1999) }\end{array}$ & $\begin{array}{l}\mathrm{H}^{2} \mathrm{O} \text { (Couvidat et } \\
\text { al., 2012) coupled } \\
\text { with SOAP (Cou- } \\
\text { vidat and Sartelet, } \\
2015 \text { ) }\end{array}$ & $\begin{array}{l}\text { Not used in this } \\
\text { study }\end{array}$ & $\begin{array}{l}\text { MEGAN v2.1 } \\
\text { (Guenther et al., } \\
\text { 2012) }\end{array}$ \\
\hline $\begin{array}{l}\text { EMEP MSC-W } \\
\text { (model rv.4.7, } \\
\text { spring 2015) }\end{array}$ & $\begin{array}{l}\text { EmChem09 (Simp- } \\
\text { son et al., 2012) }\end{array}$ & $\begin{array}{l}\text { MARS (Binkowski } \\
\text { and Shankar, 1995) }\end{array}$ & $\begin{array}{l}\text { VBS-NPAS (Simp- } \\
\text { son et al., 2012) }\end{array}$ & $\begin{array}{l}\text { Yes (Bergström et } \\
\text { al., 2012) }\end{array}$ & $\begin{array}{l}\text { (Simpson et al., } \\
\text { 2012) Based upon } \\
\text { maps of } 115 \text { tree } \\
\text { species from } \\
\text { Koeble and Seufert } \\
(2001)\end{array}$ \\
\hline $\begin{array}{l}\text { LOTOS-EUROS } \\
\text { (model version } \\
1.10 .005 \text { ) }\end{array}$ & $\begin{array}{l}\text { TNO-CBM-IV } \\
\text { (Schaap et al., } \\
\text { 2009) }\end{array}$ & $\begin{array}{l}\text { ISORROPIA II } \\
\text { (Fountoukis and } \\
\text { Nenes, 2007) }\end{array}$ & $\begin{array}{l}\text { Not used in this } \\
\text { study }\end{array}$ & $\begin{array}{l}\text { Not used in this } \\
\text { study }\end{array}$ & $\begin{array}{l}\text { (Bergström et al., } \\
\text { 2012) Based upon } \\
\text { maps of } 115 \text { tree } \\
\text { species from } \\
\text { Koeble and Seufert } \\
(2001)\end{array}$ \\
\hline $\begin{array}{l}\text { MATCH (model } \\
\text { version April 2016) }\end{array}$ & $\begin{array}{l}\text { Based on EMEP } \\
\text { MSC-W (Simpson } \\
\text { et al., 2012) with } \\
\text { modified isoprene } \\
\text { chemistry (Carter, } \\
\text { 1996; Langner et } \\
\text { al., 1998) }\end{array}$ & $\begin{array}{l}\text { RH and T } \\
\text { dependent } \\
\text { equilibrium } \\
\text { constant } \\
\text { (Mozurkewich, } \\
\text { 1993) }\end{array}$ & $\begin{array}{l}\text { Similar to VBS- } \\
\text { NPNA (Bergström } \\
\text { et al., 2012) }\end{array}$ & $\begin{array}{l}\text { Yes (Bergström } \\
\text { et al., 2012) }\end{array}$ & $\begin{array}{l}\text { (Bergström et al., } \\
\text { 2012) Based upon } \\
\text { maps of } 115 \text { tree } \\
\text { species from } \\
\text { Koeble and Seufert } \\
(2001)\end{array}$ \\
\hline $\begin{array}{l}\text { MINNI (model ver- } \\
\text { sion 4.7) }\end{array}$ & $\begin{array}{l}\text { SAPRC99 (Carter, } \\
\text { 2000) }\end{array}$ & $\begin{array}{l}\text { ISORROPIA v1.7 } \\
\text { (Nenes et al., 1998) }\end{array}$ & $\begin{array}{l}\text { SORGAM module } \\
\text { (Schell et al., 2001) }\end{array}$ & None & $\begin{array}{l}\text { MEGAN v2.04 } \\
\text { (Guenther et al., } \\
\text { 2006) }\end{array}$ \\
\hline
\end{tabular}

(including dry and wet deposition parameterizations) can be found in Colette et al. (2017). The models differ in terms of the adopted gas-phase chemistry mechanisms as well as SIA and SOA formation modules, but they all adopted the same spatial resolution, i.e., $0.25^{\circ} \times 0.40^{\circ}$. Here, we briefly describe the main characteristics of the various schemes used by the models.

Various gas-phase schemes were used to perform the gasphase chemistry (Table 1): the Carbon Bond mechanism version 4 (referred to as TNO-CBM-IV), EmChem09, MELCHIOR2 and SAPRC99.

- The TNO-CBM-IV gas-phase scheme (Schaap et al., 2009), used by the LOTOS-EUROS model, includes 33 gas-phase species and nine organic species emitted directly into the atmosphere. Most of the included organic species are lumped according to the carboncarbon bond type and only a minority of them are explicitly represented (e.g., isoprene and formaldehyde). A total of 104 chemical reactions and 14 photolytic re- actions are mapped in the TNO-CBM-IV mechanism for gas-phase chemistry.

- The EmChem09 gas-phase scheme (Simpson et al., 2012), used by EMEP MSC-W and MATCH models, include 72 species, 137 chemical reactions and 26 photochemical reactions. The rates and products were designed to be as close as possible to the IUPAC recommendations (http://www.iupackinetic.ch.cam.ac.uk/, last access: 14 November 2019) and most of the reaction coefficients were taken from Atkinson et al. (2006, 2004). The MATCH model used a modified version of isoprene chemistry based on the work of Carter (1996) and Langner et al. (1998).

- The MELCHIOR2 gas-phase scheme (Derognat et al., 2003), used by the CHIMERE model, is a reduced version of the MELCHIOR1 mechanism and it includes 120 chemical reactions and hydrocarbon degradation as in the EMEP gas-phase mechanism, with a few adaptations included for low- $\mathrm{NO}_{x}$ conditions and $\mathrm{NO}_{x}$-nitrate 
chemistry. All rate constants are taken from Atkinson et al. (1997) and De Moore et al. (1994).

- The SAPRC99 gas-phase scheme (Carter, 2000), used by the MINNI model, includes a detailed speciation of about 400 types of VOCs and with detailed reaction schemes for most of the non-aromatic hydrocarbons and oxygenates in the presence of $\mathrm{NO}_{x}$. The isoprene photooxidation is explicitly included; the "four-product" condensed isoprene mechanism considers methacrolein, methyl vinyl ketone, lumped C5 unsaturated aldehyde products (ISOPROD) and the methacrolein PAN analogue (MPAN).

To resolve the composition and phase state of inorganic aerosol, most of the models used the ISORROPIAv2.1 scheme (version 1.7 for the MINNI model and version II for LOTOS-EUROS) which assumes thermodynamic equilibrium with its gas-phase precursors (Nenes et al., 1999, 1998). The EMEP MSC-W model adopted the approach proposed by Binkowski and Shankar (1995), i.e., the MARS equilibrium module, and does not include sodium chloride and dust components, whereas the MATCH model is based on the work of Mozurkewich (1993). Transformation of $\mathrm{HNO}_{3}$ to coarse nitrate is included by all the models except MINNI.

As already mentioned, $\mathrm{NH}_{3}$ is a key ingredient for the formation of secondary inorganic aerosols. $\mathrm{NH}_{3}$ compensation points are included in LOTOS-EUROS to account for the presence of $\mathrm{NH}_{3}$ in the stomata, external leaf surfaces or at the soil surface and partially included in the EMEP MSC$\mathrm{W}$ model by assuming zero $\mathrm{NH}_{3}$ dry deposition to growing crops.

Different gas-phase and thermodynamic organic aerosol schemes with various levels of complexity were used by the modeling teams (Table 1): the volatility basis set with and without aging of SOA (Bergström et al., 2012; Simpson et al., 2012), referred to as VBS-NPAS and VBS-NPNA, respectively, the $\mathrm{H}^{2} \mathrm{O}$ mechanism (Couvidat et al., 2012) coupled with the SOAP module (Couvidat and Sartelet, 2015) and the SORGAM mechanism (Schell et al., 2001). None of the models included emission of semi-volatile organic compounds (SVOCs) and/or of intermediate-volatility organic compounds (IVOCs). LOTOS-EUROS did not enable any SOA scheme, and therefore the organic model description is not included here.

- The VBS-NPAS and VBS-NPNA organic aerosol modules, used by the EMEP MSC-W and MATCH models, respectively, assume POA emission to be non-volatile, assuming European emission inventories to consist of inert PM compounds. Semi-volatile SOA is formed from oxidation of anthropogenic and biogenic VOCs (for details regarding the volatility basis set and SOAyields, see Bergström et al., 2012). In the EMEP (VBSNPAS) model, the $\mathrm{OH}$ reaction rate for SOA aging is set to $4.0 \times 10^{-12} \mathrm{~cm}^{3}$ molecule ${ }^{-1} \mathrm{~s}^{-1}$; each reaction of the organic compounds in the gas-phase decreases the volatility by 1 order of magnitude and increases the mass by $+7.5 \%$ to account for oxygen addition (fragmentation processes are not included). SOA aging is not included in the VBS-NPNA scheme.

- The $\mathrm{H}^{2} \mathrm{O}$ organic aerosol module (Couvidat et al., 2012), used by the CHIMERE model, uses different types of surrogate organic species: hydrophilic species (which condense preferentially into an aqueous phase) and hydrophobic species (which condense only into an organic phase). These surrogate species are produced from the oxidation of volatile organic compounds. In $\mathrm{H}^{2} \mathrm{O}$, SOAs are formed from four classes of precursors: aromatic compounds, isoprene, monoterpenes and sesquiterpenes. For aromatic compounds, toluene and xylene are used as SOA precursors when reacting with the $\mathrm{OH}$ radical and without accounting for SOA aging. The $\mathrm{H}^{2} \mathrm{O}$ mechanism accounts for the effect of nitrogen oxides on SOA formation as well as the dissociation of organic acids in an aqueous phase, the oligomerization of aldehydes. More details of the scheme can be found in Couvidat et al. (2018, 2012).

- The SORGAM mechanism (Schell et al., 2001), used by the MINNI modeling system, includes four SOA precursors classes (alkanes, alkenes, aromatics and monoterpenes) to represent the contributions of anthropogenic precursors and biogenic precursors to SOA formation. VOCs are oxidized by reactions with the hydroxyl radical $(\mathrm{OH})$, ozone $\left(\mathrm{O}_{3}\right)$ and nitrate radical $\left(\mathrm{NO}_{3}\right)$. The anthropogenic SOA are formed from aromatics like toluene, xylene and cresol, from internal alkenes and long "alkanes" as those grouped together in the ALK5 and OLE2 classes, respectively, in the SAPRC99 gas-phase mechanism. Biogenic SOA is produced only by monoterpenes whose partitioning parameters are obtained from a weighted average of smog chamber experiments for $\alpha$-pinene, $\beta$-pinene, d3carene, sabinene and limonene.

\subsection{Emissions}

\subsubsection{Biogenic and natural emissions}

Emissions of biogenic volatile organic compounds (BVOCs) were not prescribed by the EDT experiments. Each participating team used their own emission model to calculate biogenic emissions.

One group of models used the Model of Emissions of Gases and Aerosols from Nature (MEGAN) v2.04 (Guenther et al., 2006) and MEGANv2.1 (Guenther et al., 2012) emission models: CHIMERE and MINNI, respectively. CHIMERE uses highly resolved spatiotemporal data (30 arcsec every $8 \mathrm{~d}$ ) generated from MODIS for leaf area index (LAI) inputs. The 30 arcsec USGS (US Geophysical 
Survey) land-use database is used to provide information on the plant functional type (PFT). The PFT is then combined with the emission factors for each functional type of Guenther et al. (2012) to compute the landscape average emission factors. MINNI derived them from the CORINE Land Cover (CLC2006) inventory. The MEGAN model is driven with meteorological variables, such as temperature, wind speed, humidity, solar radiation and soil moisture. The leaf area index retrieved from the Terra MODIS satellite is used to simulate the vegetation growth $(8 \mathrm{~d}$ and 1 -month average LAI data at $0.25^{\circ} \times 0.25^{\circ}$ resolution for CHIMERE and MINNI, respectively). Common BVOCs species such as isoprene, $\alpha$ pinene as well as other classes of monoterpenes are generated for each hour and grid cell of the domain. In the CHIMERE model, emissions of sesquiterpenes are also included and used as an input for SOA chemistry. More information on the MEGAN emission algorithms can be found in Guenther et al. (2006, 2012).

The second group of models (LOTOS-EUROS, MATCH and EMEP MSC-W) used a detailed tree inventory of 115 species for 30 European countries based on the work of Koeble and Seufert (2001) and aggregated tree species based on land-cover types. For this group of models, the environmental factors to derive biogenic emissions include the light correction factor $\left(\gamma_{\mathrm{L}}\right)$ and the temperature correction function $\left(\gamma_{\mathrm{T}}\right)$, which are applied to three types of emission categories: isoprene, pool-dependent monoterpenes and light-dependent monoterpenes based on Guenther et al. (1993). More information on the EMEP MSC-W BVOC emission algorithm can be found in Simpson et al. (2012).

Finally, sea salt, emitted in water droplets from the sea during high wind speed conditions and as a result of breaking of waves and/or bursting of air bubbles, is included in all the models, based on different schemes, as described in Colette et al. (2017). Windblown dust emission were taken into account by all the models except MATCH, while road traffic dust resuspension was only included in the EMEP MSC-W model (Colette et al., 2017).

\subsubsection{Anthropogenic emissions}

Anthropogenic gridded emissions by country and activity, i.e., SNAP (Selected Nomenclature for reporting of Air Pollutants) codes, were estimated using the Greenhouse gas Air Pollution Interactions and Synergies (GAINS) model (Amann et al., 2011). Emission of $\mathrm{SO}_{x}, \mathrm{NO}_{x}, \mathrm{NH}_{3}$, nonmethane volatile organic compounds (NMVOCs) as well as primary $\mathrm{PM}_{2.5}, \mathrm{PM}_{10}$, black carbon and primary organic aerosol were prepared at a $0.25^{\circ} \times 0.40^{\circ}$ resolution (latitude $\times$ longitude). Anthropogenic emissions were calculated for the years 1990, 1995, 2000, 2005 and 2010, and linearly interpolated by country and activity sector for the 5-year periods to obtain the continuous 21-year emission dataset. Data for the different emission sectors were obtained from Eurostat (http://ec.europa.eu/eurostat, last ac- cess: 14 November 2019), the International Energy Agency (IEA, 2012) and the UN Food and Agriculture Organization (FAO) (http://www.fao.org/statistics/en/, last access: 14 November 2019). Additionally, data from the International Fertilizer Association (IFA) and the COPERT model (Athanasiadis et al., 2009) were used for the agriculture and transportation sectors, respectively. An error in primary particulate emission matter for Russia, north Africa and maritime areas for the period of 1991-1999 was identified at the end of the exercise. However, the effect of the error was estimated to be very limited (Theobald et al., 2019).

The complete anthropogenic emission dataset accounts for source-specific emission limits as well as for various European air quality directives (e.g., the UNECE Gothenburg Protocol; UNECE, 1999). This emission dataset, referred to as ECLIPSE_V5, was delivered by IIASA as country national totals by activity sector. It was subsequently spatialized by INERIS on the EURODELTA-Trends grid for use in the CTMs using the gridding process described in Terrenoire et al. (2015) and Bessagnet et al. (2016). For the residential heating sector (SNAP2), a proxy based on population density was applied using a bottom-up inventory available for France. More information about the regridding can be found in Colette et al. (2017).

\subsubsection{Meteorological data}

To provide meteorological inputs to the modeling teams, dynamically downscaled regional climate model simulations were used in combination with ERA-Interim global reanalysis data (Dee et al., 2011). The Weather Research and Forecasting model (WRF version 3.3.1; Skamarock et al., 2008) was used at a resolution of $0.44^{\circ}$ to generate the meteorological parameters. To reduce the uncertainty of the meteorological data, WRF was re-run with ERA-Interim reanalysis data in grid-nudging mode as described in Stegehuis et al. (2015) and subsequently interpolated at a $25 \mathrm{~km}$ resolution to match the EDT grid, although there were a few differences between the procedures of the modeling team. LOTOS-EUROS used RACMO2-downscaled data and MATCH used HIRLAMdownscaled data. More information on the meteorological inputs can be found in Colette et al. (2017).

\subsubsection{Observational data and trend assessment}

The observations are reported to EMEP, and the original time series are available in EBAS (http://ebas.nilu.no, last access: 14 November 2019). The annual observational datasets chosen for the trend assessment have passed the completeness criteria of $75 \%$ of data available over the full 1990-2010 period and have undergone visual screening tests. The secondary dataset with annual and seasonal average concentrations is available from the webpage set up by the Task Force on Measurements and Modeling (TFMM) for this study (https://wiki.met.no/emep/emep-experts/tfmmtrendstations, 
$\mathrm{SO}_{2}$ observational sites

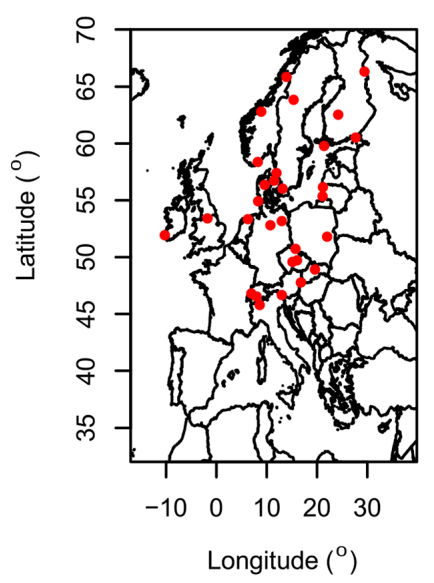

$\mathrm{TNO}_{3}$ observational sites

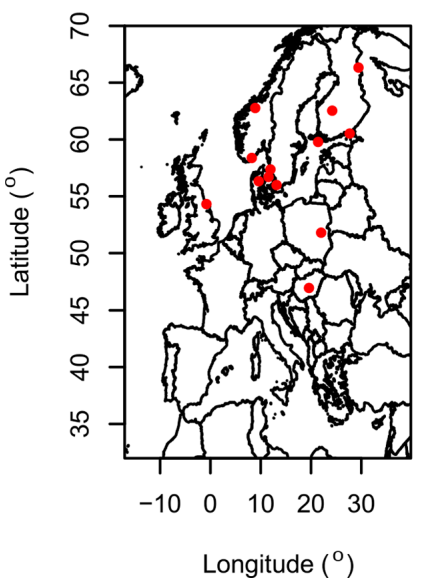

$\mathrm{SO}_{4}{ }^{2-}$ observational sites

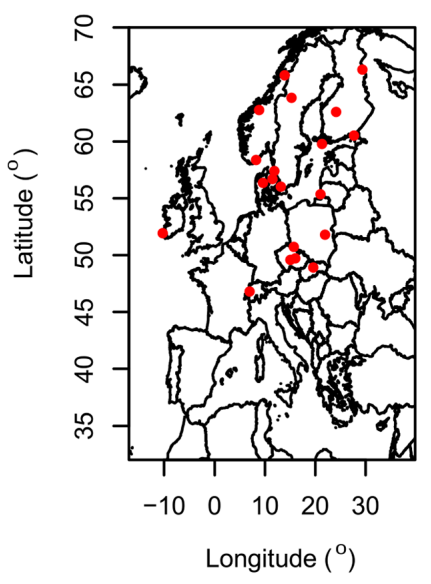

$\mathrm{TNH}_{\mathrm{x}}$ observational sites

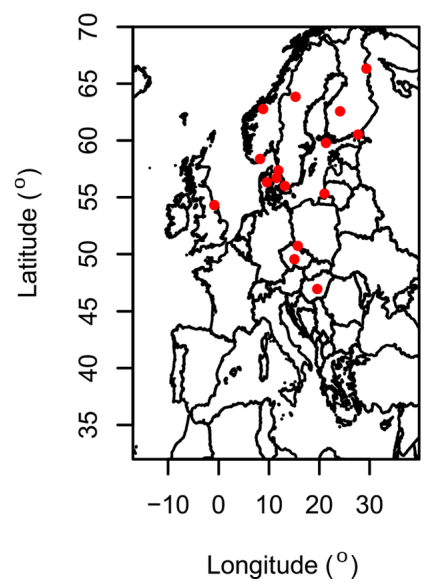

Figure 2. Locations of the observational sites (red dots). The numbers of observational sites available for each species are 30, 20, 25, 13 and 16 for $\mathrm{SO}_{2}, \mathrm{SO}_{4}^{2-}, \mathrm{NO}_{2}, \mathrm{TNO}_{3}$ and $\mathrm{TNH}_{x}$, respectively.

last access: 14 November 2019). The datasets include yearly measurements of long-term air concentrations of sulfur dioxide $\left(\mathrm{SO}_{2}\right)$, particle sulfate $\left(\mathrm{SO}_{4}^{2-}\right)$, nitrogen dioxide $\left(\mathrm{NO}_{2}\right)$ total nitrate $\left(\mathrm{TNO}_{3}=\mathrm{HNO}_{3}(\mathrm{~g})+\mathrm{NO}_{3}^{-}(\mathrm{p})\right)$ and total ammonium $\left(\mathrm{TNH}_{x}=\mathrm{NH}_{3}(\mathrm{~g})+\mathrm{NH}_{4}^{+}(\mathrm{p})\right)$ performed in Europe between 1990 and 2010. Overall, the numbers of observational sites available for each of the species are $30,20,25,13$ and 16 for $\mathrm{SO}_{2}, \mathrm{SO}_{4}^{2-}, \mathrm{NO}_{2}, \mathrm{TNO}_{3}$ and $\mathrm{TNH}_{x}$, respectively. Figure 2 illustrates the geographical distribution of the observational sites for each of the species, all classified as rural background stations. It can be noted that most of the stations are located over the northern and central parts of the domain, therefore limiting the evaluation of the model results to these specific sites. The complete list of the observational sites is reported in Table S1.

$\mathrm{NO}_{2}$ is mainly sampled with the manual method where $\mathrm{NO}_{2}$ is selectively absorbed on impregnated glass sinters.
Some sites do, however, use a chemiluminescence monitor with a molybdenum converter, which is not selective for $\mathrm{NO}_{2}$; thus, these measurements might be biased, and this is especially important in areas with low concentrations (Reed et al., 2016), but it is not assumed that the trends will be largely affected when same method is used during the whole period. The other components are mostly measured using a filterpack sampler with no size cutoff in the inlet. The threestage filterpack separates gas and aerosol species, but for nitrogen compounds this separation might be biased due to the volatile nature of $\mathrm{NH}_{4} \mathrm{NO}_{3}$. Therefore, $\mathrm{TNO}_{3}$ and $\mathrm{TNH}_{x}$ are usually used for robust estimate of the atmospheric nitrogen loading (Tørseth et al., 2012). However, it is recommended to report the measurements of all the species since it may give valuable insight into the gas-particle ratio despite possible biases. Details of the method used are found in the annual data report (i.e., EMEP, 2012, for the 2010 data). 
Table 2. Relative and absolute trends in emissions of $\mathrm{SO}_{x}, \mathrm{NO}_{x}, \mathrm{NH}_{3}$ and NMVOCs in the EURODELTA-Trends exercise (whole domain). Trends are reported for the entire 1990-2010 period as well as for two subperiods, 1990-2000 and 2000-2010. The linear trends were calculated using the Theil-Sen method (Sen, 1968).

\begin{tabular}{lrr|rr|rr}
\hline & \multicolumn{2}{c|}{$1990-2000(\mathrm{P} 1)$} & $2000-2010(\mathrm{P} 2)$ & \multicolumn{1}{c}{$1990-2010(\mathrm{PT})$} \\
\cline { 2 - 7 } & $\begin{array}{r}\text { Total relative } \\
\text { change (\%) }\end{array}$ & $\begin{array}{r}\text { Absolute change per } \\
\text { year (ktons yr }\end{array}$ & $\begin{array}{r}\text { Total relative } \\
\text { change (\%) }\end{array}$ & $\begin{array}{r}\text { Absolute change per } \\
\text { year (ktons yr }\end{array}$ & $\begin{array}{r}\text { Total relative } \\
\text { change }(\%)\end{array}$ & $\begin{array}{r}\text { Absolute change per } \\
\text { year }\left(\mathrm{ktons} \mathrm{yr}^{-1}\right)\end{array}$ \\
\hline $\mathrm{SO}_{x}$ & -54 & -1952 & -37 & -668 & -69 & -1061 \\
$\mathrm{NO}_{x}$ & -25 & -659 & -17 & -356 & -39 & -510 \\
$\mathrm{NH}_{3}$ & -19 & -129 & -6 & -31 & -15 & -45 \\
$\mathrm{NMVOC}$ & -33 & -812 & -33 & -525 & -59 & -705 \\
\hline
\end{tabular}

The linear trends for each species and observational site were calculated with the Theil-Sen method (Sen, 1968) and their significance was evaluated at $95 \%$ confidence level $(p<0.05)$ using the non-parametric Mann-Kendall test (Kendall, 1948; Mann, 1945). Trends in observational data were compared with trends in modeled data calculated with the same methodology. Since anthropogenic emissions did not decline linearly during the full period covered by the experiment (1990-2010, referred to as PT), and larger emissions reductions are expected during the early 1990s, the trend analysis was performed for two subperiods: the first period between 1990 and 2000, referred to as P1, and the second period between 2000 and 2010, referred as to P2. The linear trends are presented as relative changes with respect to the years 1990 and 2000 for the two 11-year periods and as relative changes with respect to the year 1990 for the full 21-year period. In addition, to provide a more comprehensive picture of the trends in the air pollutant concentrations, the trend analysis was also performed for several subregions adapted from the commonly used the Prediction of Regional scenarios and Uncertainties for Defining EuropeaN Climate change risks and Effects (PRUDENCE) climatic zone classification (http://ensemblesrt3.dmi.dk/quicklook/regions.html, last access: 14 November 2019). The extension of the subregions used in the study is reported in Fig. 1.

The evaluation of modeled SOA was performed using an extensive dataset of secondary organic aerosol concentrations retrieved with positive matrix factorization (PMF) analysis (Paatero, 1999) and recently compiled by Tsimpidi et al. (2016). This dataset includes SOA average concentrations at various sites in Europe during the P2 period. In order to remove local pollution events, likely not included in emission inventories, stations with average SOA concentrations higher than $7 \mu \mathrm{g} \mathrm{m}^{-3}$ during the measurement period were excluded from the analysis (three sites excluded - in total, 28 sites were kept: six urban sites, eight urban downwind sites and $14 \mathrm{rural} / \mathrm{remote}$ sites). Most of the measurements were performed during short campaigns using aerosol mass spectrometers (AMSs) in different periods of the years, lasting from about 2 weeks to 1 month. The spatial distribution of the stations is presented in Fig. S1. The complete list of stations used is reported in Table S2 along with information regarding the year and the seasons during which measurements were made.

\section{Results and discussion}

\subsection{Trends in anthropogenic emissions}

Table 2 reports the absolute and relative trends in $\mathrm{SO}_{x}, \mathrm{NO}_{x}$, $\mathrm{NH}_{3}$ and NMVOC emissions for the full 1990-2010 period as well as for the P1 and P2 periods over the entire domain. For the full period, $\mathrm{SO}_{x}$ emissions show a decline of about $69 \%$. $\mathrm{SO}_{x}$ emissions declined faster during the $\mathrm{P} 1$ period compared with the P2 with decreases of $54 \%$ and $37 \%$, respectively (Table 2), with larger reductions occurring in Germany and eastern parts of the domain (Theobald et al., 2019). The large reduction in $\mathrm{SO}_{x}$ emissions was largely attributed to emission reductions in the "combustion in energy and transformation industries" sector, largely achieved by the switch to low-sulfur-containing fuels (e.g., natural gas) and the adoption of desulfurization technologies in large industries.

$\mathrm{NO}_{x}$ emissions were reduced by $25 \%$ during the $\mathrm{P} 1$ period and by $17 \%$ during the $\mathrm{P} 2$ period with larger reductions occurring in Russia, Ukraine, Germany and the UK (Theobald et al., 2019). These reductions were mainly achieved through emission reductions in the road transport sector following the introduction of the new EURO standards for passenger cars. However, in 2010, this sector still represented the most important source of anthropogenic $\mathrm{NO}_{x}$ emissions in Europe (EEA, 2012). Important $\mathrm{NO}_{x}$ emission reductions were also achieved thanks to the adoption of low- $\mathrm{NO}_{x}$ burners and selective and non-selective catalytic reduction measures for the "combustion in energy and transformation industries" sector.

$\mathrm{NH}_{3}$ emissions declined only a little compared to $\mathrm{SO}_{x}$ and $\mathrm{NO}_{x}$ emissions. $\mathrm{NH}_{3}$ emission mainly arises from agricultural activities, which had less stringent controls compared to $\mathrm{SO}_{x}$ and $\mathrm{NO}_{x}$ emission ceilings. $\mathrm{NH}_{3}$ emissions declined by $19 \%$ over the P1 period but only by $6 \%$ over the P 2 period. 
Table 3. Modeled and observed mean relative trends of $\mathrm{NO}_{2}$ and $\mathrm{SO}_{2}$ for the P1 (1990-2000), P2 (2000-2010) and PT (1990-2010) periods and percentage of points in Fig. 3 within a factor of 2 of the observed trends.

\begin{tabular}{lrrrrrr}
\hline NO $_{2}$ & P1 (\%) & P2 (\%) & PT (\%) & $\begin{array}{r}\text { P1 (\% of points } \\
\text { within a factor of 2) }\end{array}$ & $\begin{array}{r}\text { P2 (\% of points } \\
\text { within a factor of 2) }\end{array}$ & $\begin{array}{r}\text { PT (\% of points } \\
\text { within a factor of 2) }\end{array}$ \\
\hline Obs & -25 & -12 & -36 & - & - & - \\
EMEP MSC-W & -19 & -22 & -44 & 56 & 56 & 52 \\
CHIMERE & -23 & -25 & -47 & 52 & 48 & 56 \\
MATCH & -20 & -26 & -46 & 64 & 52 & 52 \\
LOTOS-EUROS & -21 & -22 & -46 & 48 & 48 & 52 \\
MINNI & -19 & -24 & -44 & 52 & 56 & 56 \\
\hline & & & & P1 (\% of points & P2 (\% of points & PT (\% of points \\
SO & P1 $(\%)$ & P2 (\%) & PT (\%) & within a factor of 2) & within a factor of 2) & within a factor of 2) \\
\hline Obs & -82 & -47 & -97 & - & - & - \\
EMEP MSC-W & -76 & -54 & -97 & 100 & 83 & 100 \\
CHIMERE & -69 & -34 & -91 & 97 & 63 & 100 \\
MATCH & -67 & -48 & -88 & 100 & 67 & 100 \\
LOTOS-EUROS & -69 & -40 & -88 & 97 & 80 & 100 \\
MINNI & -64 & -41 & -84 & 97 & & 100 \\
\hline
\end{tabular}

Emissions of NMVOCs showed a decline of $59 \%$ over the full 1990-2010 period with similar relative reductions achieved during the P1 and P2 periods: $33 \%$ per period. NMVOC emission reductions were mainly driven by the road transport sector, and by the year 2010, most of the NMVOC emissions arose from the use of solvents (EEA, 2012). Huang et al. (2017) compiled a global gridded dataset of speciated NMVOC emissions for the 1970-2010 period and analyzed the trends. Among the different world regions, North America and Europe were reported to have reduced their NMVOC emissions since 1970 due to the introduction of EURO emission standards for vehicles. A significant reduction of formaldehyde emissions was reported in 2010 compared with 2000, mainly because of the increasing adoption of EURO standards and the transition from coal to cleaner fuels (e.g., natural gas). The latter resulted in a substantial decrease in the aromatic species and in an increase in the contribution of alkanes and alkanals to the emissions of NMVOCs (Huang et al., 2017).

\subsection{Trends in inorganic species}

\subsubsection{Comparison of modeled and observed $\mathrm{SO}_{2}$ and $\mathrm{NO}_{2}$ concentrations trends}

Figure 3 and Table 3 report the mean relative trends of all the sites included in the analysis (Table S1).

For $\mathrm{SO}_{2}$, the observed relative reductions were $82 \%, 47 \%$ and $97 \%$ for the P1, P2 and full periods, respectively (Fig. 3 and Table 3). The models indicate very similar ranges of $\mathrm{SO}_{2}$ reductions, i.e., $64 \%-76 \%$ for the $\mathrm{P} 1$ periods, $34 \%-54 \%$ for the P2 period and between $84 \%$ and $97 \%$ for the full period, depending on the model (Table 3). This is in line with the emission reduction trends presented in Sect. 3.1 and with (a) $\mathrm{NO}_{2}$ concentrations

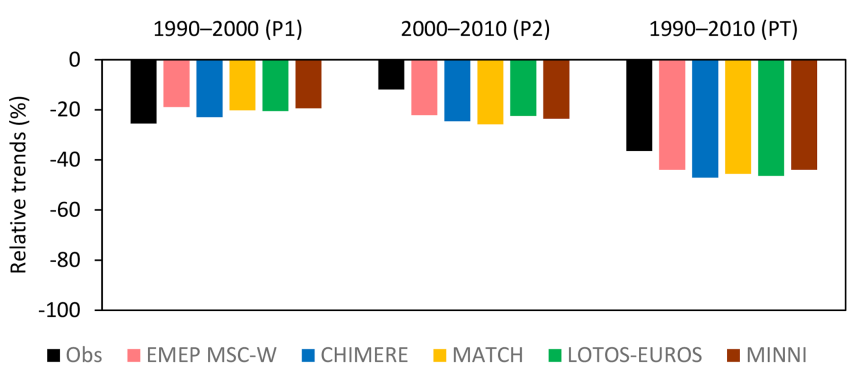

(b) $\mathrm{SO}_{2}$ concentrations

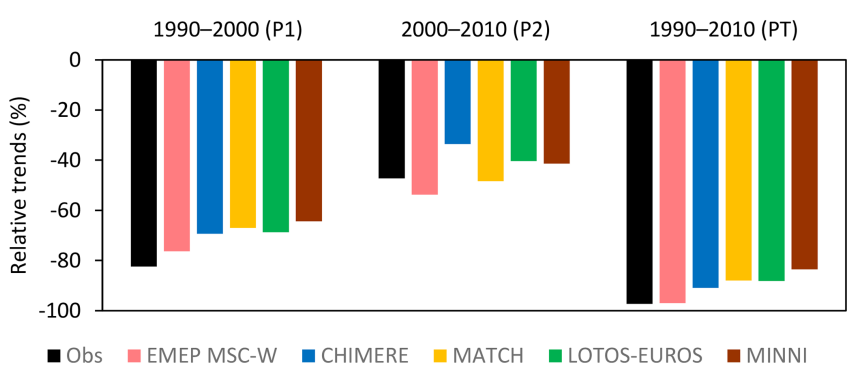

Figure 3. Modeled and observed (obs) mean relative trends of $\mathrm{NO}_{2}$ (a) and $\mathrm{SO}_{2}$ concentrations (b) for the P1 (1990-2000), P2 (2000-2010) and PT (1990-2010) periods.

previous trend studies for Europe (Tørseth et al., 2012). Table 3 also reports the fraction of model estimates within a factor of 2 of the observed trends. Most of the models were able to reproduce the observed $\mathrm{SO}_{2}$ trends within a factor of 2 at most of the individual sites (Fig. 3 and Table 3) and with model performance being better during the $\mathrm{P} 1$ period compared with P2. 

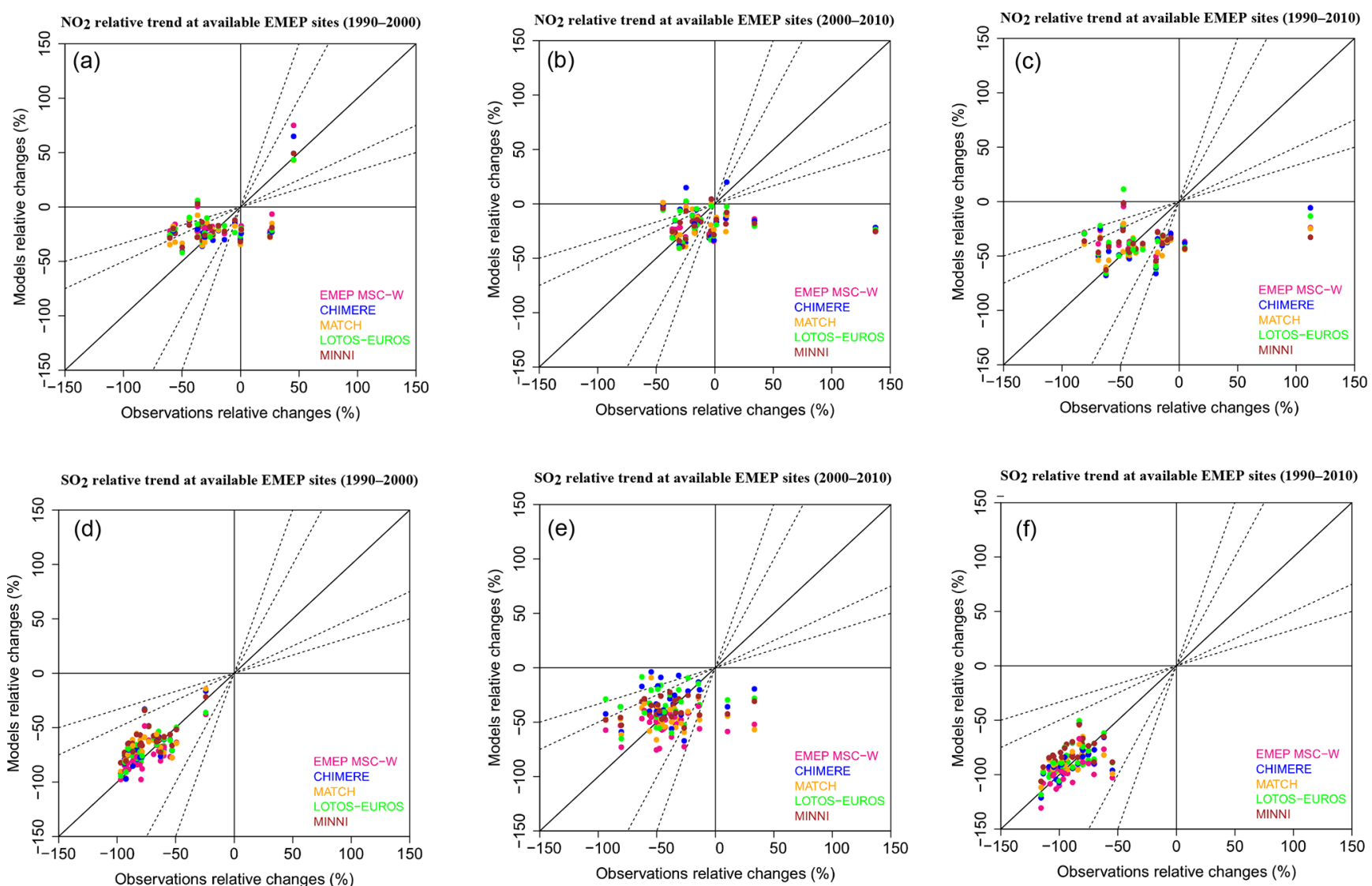

Figure 4. Modeled and observed $\mathrm{NO}_{2}$ (a-c) and $\mathrm{SO}_{2}$ (d-f) relative trends for the P1 (1990-2000), P2 (2000-2010) and PT (1990-2010) periods (left to right). The continuous line indicates the $1: 1$ line, and the dotted lines indicate the $1: 2$ and $1: 3$ lines (and their reciprocals).

Overall, the observations indicate relative reductions of $25 \%, 12 \%$ and $36 \%$ in $\mathrm{NO}_{2}$ concentrations for the $\mathrm{P} 1$, $\mathrm{P} 2$ and PT, respectively, with the models estimating similar ranges of relative reductions, i.e., $19 \%-23 \%$ for the P1 period, $22 \%-26 \%$ for the $\mathrm{P} 2$ period and $44 \%-47 \%$ for the full period, depending on the model (Table 3 ). Only about half of the individual observed trends were reproduced within a factor of 2 by individual models and all models performed worse in the second period (P2), overestimating the observed trends (Fig. 4 and Table 3). Such behavior could indicate possible difficulties for CTMs in capturing long-term trends at relatively low concentrations with small annual changes, typical of the $\mathrm{P} 2$ period.

Figure 5 shows the percentage of statistically significant/non-significant increasing/decreasing observed and modeled $\mathrm{SO}_{2}$ and $\mathrm{NO}_{2}$ trends.

For $\mathrm{SO}_{2}$, most of the stations had significant decreasing trends in concentrations during the P1 period, with only a small fraction of the stations with non-significant decreasing trends. All the models were able to reproduce this pattern, albeit with a slight overestimation of the significant decreasing fraction. During the P2 periods, most of the models tend to overestimate the number of significant trends, with
CHIMERE and LOTOS-EUROS being closer to the fraction of significant/non-significant decreasing trends indicated by the observations. For the full period (PT), the agreement between the modeled and observed fractions of significant/nonsignificant increasing/decreasing appears very good, mainly because of the larger number of data points in the time series, and with all the sites indicating significant observed and modeled decreasing trends.

For $\mathrm{NO}_{2}$, the models were able to reproduce the observed fraction of significant/non-significant increasing/decreasing trends in the P1 period, with most of the models indicating a significant decrease in $\mathrm{NO}_{2}$ concentrations at most of the stations (slightly lower for EMEP MSC-W). The analysis for the $\mathrm{P} 2$ period shows that the reduced fraction of observed significant decreasing trends compared with the P1 period was only partially reproduced by the models, all of them tending to overestimate the fraction of significantly decreasing trends (Fig. 5). Again, a possible explanation for the degraded model performance during the $\mathrm{P} 2$ period could be related to the relatively low pollutant concentrations, which might be challenging to model at such coarse resolution, as well as to uncertainties in the measurement data (see Sect. 2.3.4). One site in Ireland (IE0001R) was the only site 


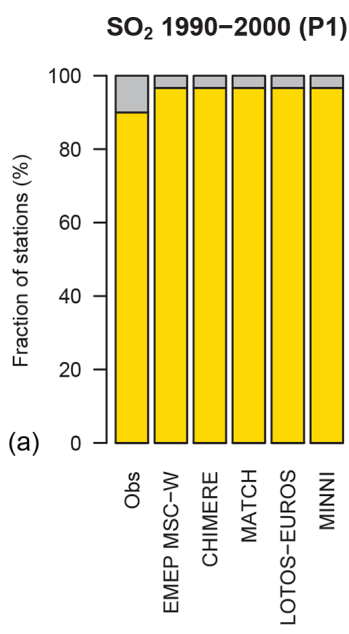

$\mathrm{NO}_{2}$ 1990-2000 (P1)

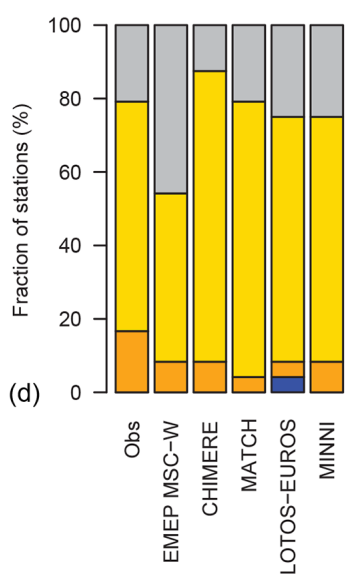

$\mathrm{SO}_{2}$ 2000-2010 (P2)

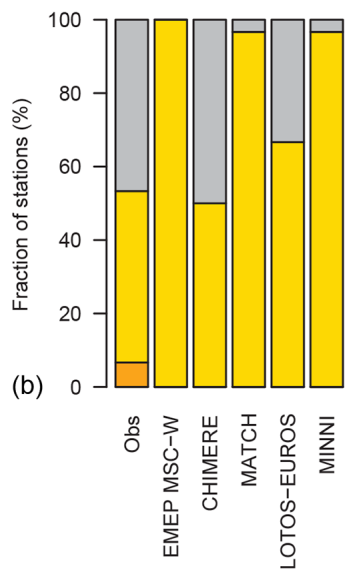

$\mathrm{NO}_{2}$ 2000-2010 (P2)

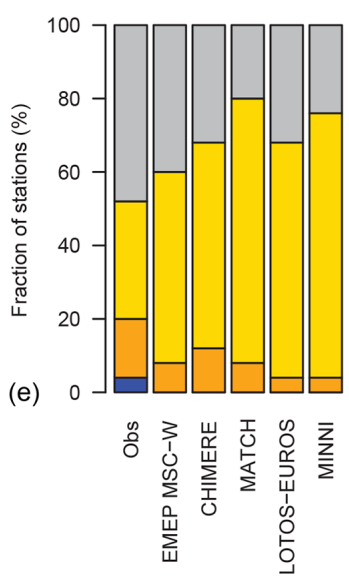

$\mathrm{SO}_{2}$ 1990-2010 (PT)

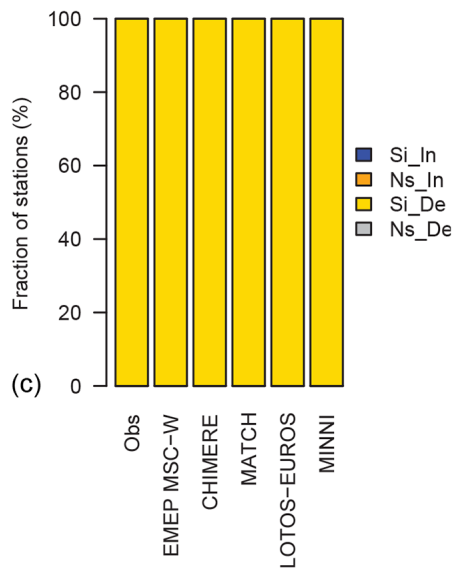

$\mathrm{NO}_{2}$ 1990-2010 (PT)

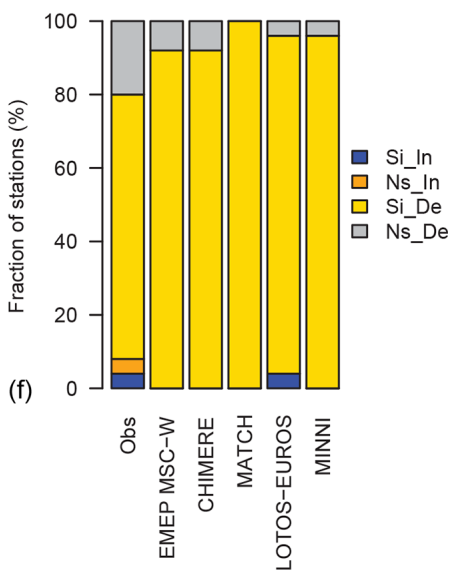

Figure 5. Percentage of statistically significant/non-significant ( $\mathrm{Si}, \mathrm{Ns}$ ) increasing/decreasing (In, De) trends in the observations and modeled data for $\mathrm{SO}_{2}$ (a-c) and $\mathrm{NO}_{2}$ (d-f) for the P1 (1990-2000), P2 (2000-2010) and PT (1990-2010) periods (from left to right). The number observational sites are 30 and 25 for $\mathrm{SO}_{2}$ and $\mathrm{NO}_{2}$, respectively.

with significant increasing observed trends during the $\mathrm{P} 1$ and PT periods, a result which was not reproduced by any of the models (the significant increase in the LOTOS-EUROS model is for the SE0014R station located in Sweden).

An additional trend analysis was performed using a generalized least squares (GLS) fit model that accounts for the temporal autocorrelation of the data. The results from the GLS model were in line with the one predicted by the TheilSen and the Mann-Kendall methods (Fig. S2 and Table S3) and with the GLS model showing a slightly higher fraction of non-significant decreasing trends during the P1, P2 and PT periods.

Model performance for $\mathrm{SO}_{2}$ and $\mathrm{NO}_{2}$ was additionally evaluated by calculating the mean fractional bias (MFB) and mean fractional error (MFE) for both the $\mathrm{P} 1$ and $\mathrm{P} 2$ periods separately (Appendix A). Recommended model performance criteria (MFB $\leq \pm 60 \%$, MFE $\leq+75 \%$ ) as well as the performance goal (MFB $\leq \pm 30 \%, \mathrm{MFE} \leq+50 \%$ ) proposed by
Boylan and Russell (2006) were achieved in both periods by most of the models apart for $\mathrm{SO}_{2}$ for MINNI during the P1 and $\mathrm{P} 2$ periods and for $\mathrm{MATCH}$ during the $\mathrm{P} 2$ period, where only the model performance criteria were achieved (Fig. S4). In addition, the evolution of the MFB over the full 19902010 period does not indicate any substantial change in 2010 compared to the first year of the exercise (i.e., 1990) with the exception of $\mathrm{SO}_{2}$, which tends to be slightly more positively biased in the latter part of the period compared to 1990 (apart from EMEP MSC-W; Fig. S5).

\subsubsection{Comparisons of modeled and observed $\mathrm{SO}_{4}^{2-}$, $\mathrm{TNO}_{3}$ and $\mathrm{TNH}_{x}$ concentration trends}

Figure 6 shows the mean modeled and observed relative trends in $\mathrm{SO}_{4}^{2-}, \mathrm{TNH}_{x}$ and $\mathrm{TNO}_{3}$ for all the sites included in the analysis (Table S1). Consistent with the gas-phase analysis, the trends are reported for the two subperiods, i.e., 1990- 

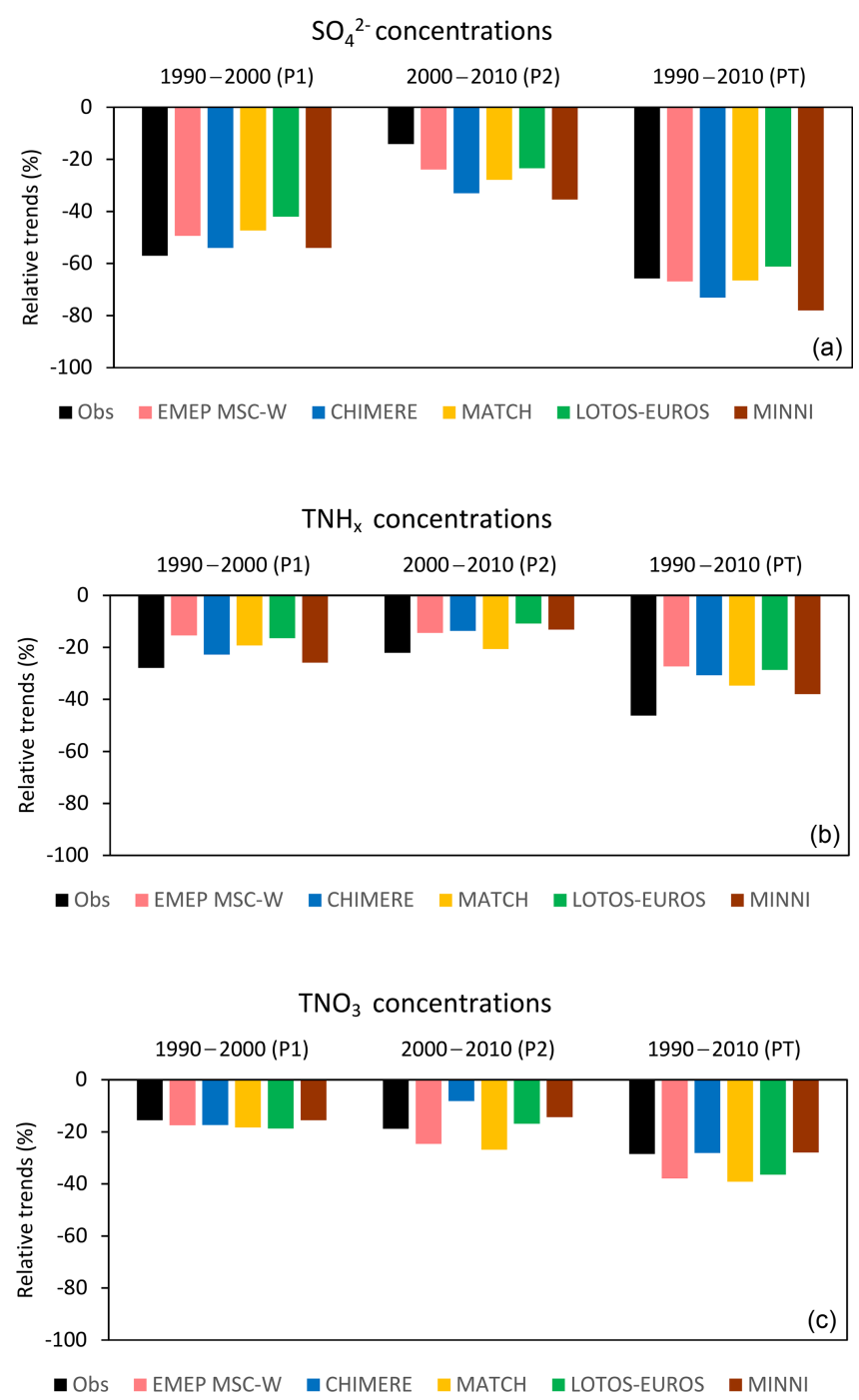

Figure 6. Modeled and observed (obs) mean relative trends in (a) $\mathrm{SO}_{4}^{2-}$, (b) $\mathrm{TNH}_{x}$ and (c) $\mathrm{TNO}_{3}$ concentrations for the P1 (1990-2000), P2 (2000-2010) and PT (1990-2010) periods.

2000 (P1) and 2000-2010 (P2), as well as for the full period (PT).

Overall, the observations indicated that concentrations of $\mathrm{SO}_{4}^{2-}$ declined by $57 \%, 14 \%$ and $66 \%$ for the $\mathrm{P} 1, \mathrm{P} 2$ and PT periods (mean of all the stations; Fig. 6 and Table 4), with the models indicating relative reductions of $42 \%-54 \%$ for the P1 periods, $23 \%-35 \%$ for the P2 period and $61 \%-$ $78 \%$ for the full period, depending on the models. The reductions in $\mathrm{SO}_{4}^{2-}$ concentrations were larger during $\mathrm{P} 1$ than during the P2 period and most of the model estimates were within a factor of 2 of the observed values for all the periods (Fig. 7 and Table 4). Two sites, one in Ireland (IE0001R) and one in Poland (PL0003R), showed an increase in $\mathrm{SO}_{4}^{2-}$ concentrations (Fig. 7), which none of the models were able to reproduce.
The percentage of statistically significant/non-significant increasing/decreasing trends in the observed and modeled $\mathrm{SO}_{4}^{2-}$ trends is reported in Fig. 8, showing good agreement between the observed and modeled significance (and their direction) for the P1 and PT periods, whereas all the models tend to overpredict the number of statistically significant increasing trends during the $\mathrm{P} 2$ period. Statistically significant increasing trends in $\mathrm{SO}_{4}^{2-}$ concentrations were only observed at the PL0003R site in Poland during the P2 period (Fig. 8), a result which none of the models were able to reproduce. Interestingly, observed $\mathrm{SO}_{4}^{2-}$ concentrations declined less than those of $\mathrm{SO}_{2}$ (Table 3), a behavior also reproduced by all the models. The non-linear dependencies between the reduction in $\mathrm{SO}_{2}$ and $\mathrm{SO}_{4}^{2-}$ concentrations are influenced by different factors. First, the strong reduction in $\mathrm{SO}_{x}$ emissions will increase the availability of $\mathrm{OH}$ radicals, which will directly enhance the homogeneous reaction rate of $\mathrm{SO}_{2}$. Second, all the models account for the dependence of the aqueous chemistry of $\mathrm{SO}_{2}$ on $\mathrm{pH}$ levels. Thus, heterogeneous reactions of $\mathrm{SO}_{2}$ are also expected to proceed more efficiently due to the increase of $\mathrm{pH}$ levels over time.

Observations of $\mathrm{TNH}_{x}$ reveal that concentrations declined by $28 \%, 22 \%$ and $46 \%$ for P1, P2 and PT, respectively (Table 4). In general, most of the models underpredict the relative changes; the modeled relative reductions for the P1, P2 and PT periods were $15 \%-26 \%, 14 \%-21 \%$ and $27 \%-$ $38 \%$, respectively, with the $\mathrm{P} 1$ period showing only a minor fraction of the data points within a factor of 2 (Fig. 7 and Table 4). Indeed, large uncertainties remain in terms of ammonia emissions, which might affect model performance for $\mathrm{TNH}_{x}$. Moreover, we would like to underline that none of the participating models accounted for the influence of meteorology (e.g., temperature) on ammonia emissions and relied on static emission profiles provided by the EURODELTA exercise. Recent studies, however, have shown that better agreement in terms of the modeled ammonia concentrations can be achieved when ammonia emissions are modulated with local meteorological conditions (Backes et al., 2016; Hendriks et al., 2016). Compared with the other investigated species, a larger variation in terms of the significance of the trends can be seen in Fig. 8, with most of the models tending to overestimate the fraction of significant decreasing trends during the P2 period. Statistically significant increasing trends in observed $\mathrm{TNH}_{x}$ concentrations were found at one station in Norway (NO0039R) for the full period (PT), with none of the models being able to reproduce this feature.

$\mathrm{TNO}_{3}$ concentrations, on the other hand, declined to a lesser extent than those of $\mathrm{SO}_{4}^{2-}$ and $\mathrm{TNH}_{x}$. For all periods, the observed relative changes in $\mathrm{TNO}_{3}$ concentration were $16 \%, 19 \%$ and $29 \%$, for the P1, P2 and PT periods, respectively, with the models estimating similar ranges for the $\mathrm{P} 1$ and $\mathrm{P} 2$ periods, i.e., $16 \%-19 \%, 8 \%-27 \%$ and $28 \%-$ $39 \%$, for the P1, P2 and PT periods, respectively (Fig. 6 and Table 4). Most of the model estimates were more than a factor of 2 larger than the observed values for the P1 

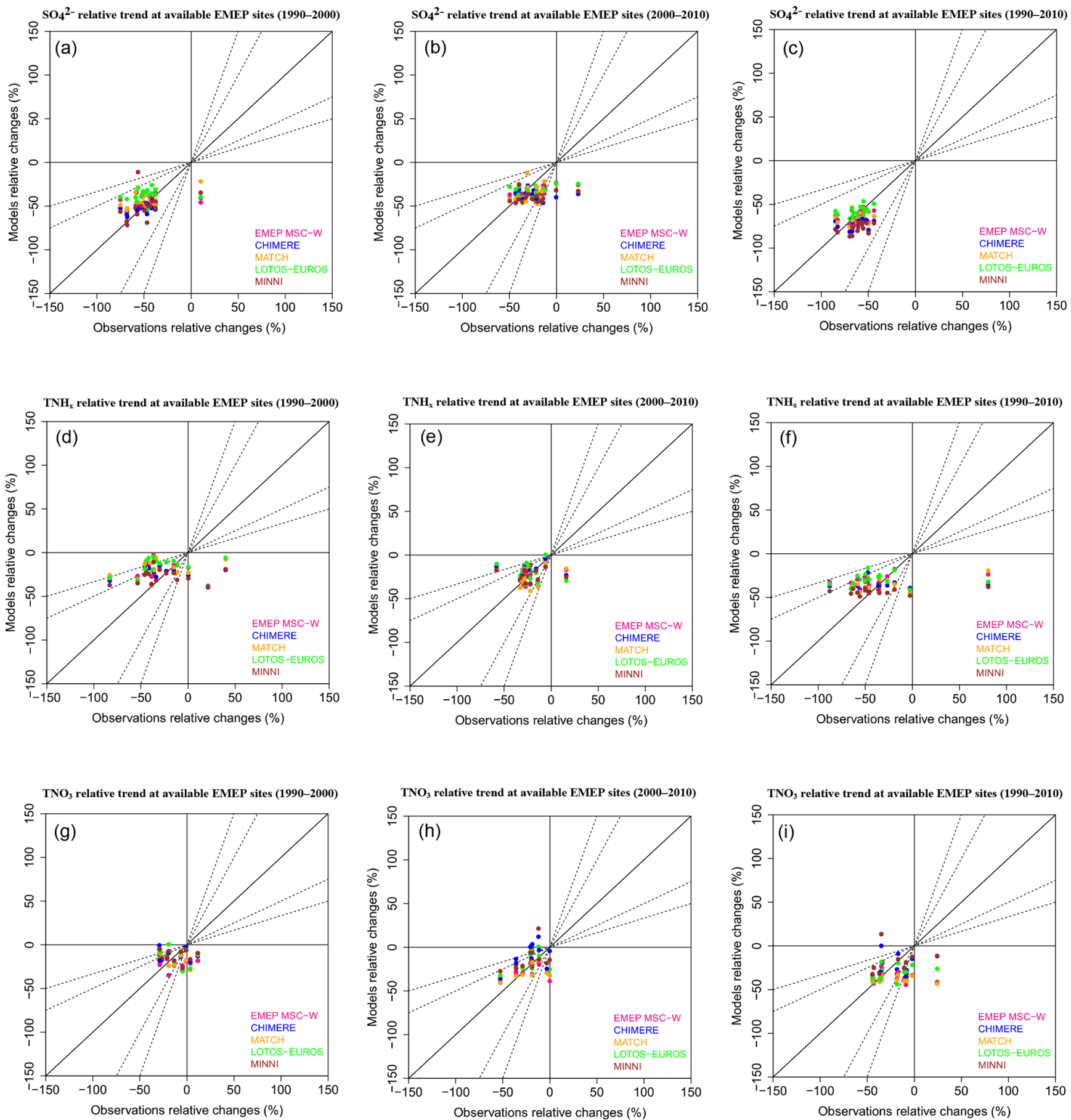

Figure 7. Modeled and observed $\mathrm{SO}_{4}^{2-}(\mathbf{a}-\mathbf{c}), \mathrm{TNH}_{x}(\mathbf{d}-\mathbf{f})$ and $\mathrm{TNO}_{3}$ (g-i) relative trends for the P1 (1990-2000), P2 (2000-2010) and PT (1990-2010) periods (left to right). The continuous line indicates the $1: 1$ line, and the dotted lines indicate the $1: 2$ and $1: 3$ lines (and their reciprocals). 

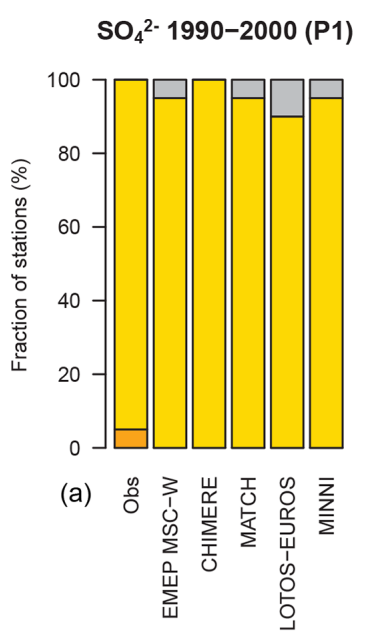

$\mathrm{TNH}_{\mathrm{x}}$ 1990-2000 (P1)

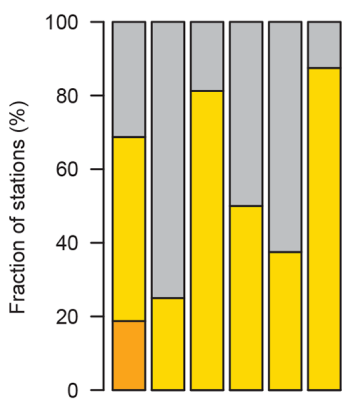

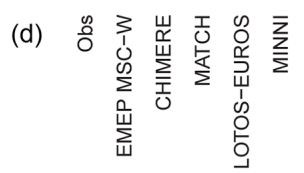

$\mathrm{TNO}_{3}$ 1990-2000 (P1)

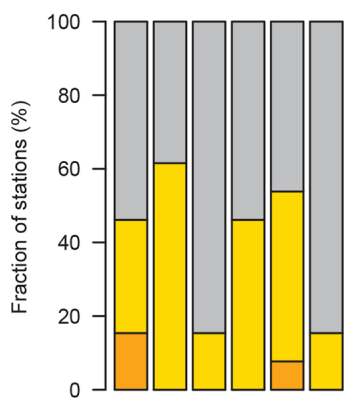

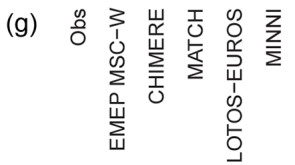

$\mathrm{SO}_{4}{ }^{2-} 2000-2010(\mathrm{P} 2)$

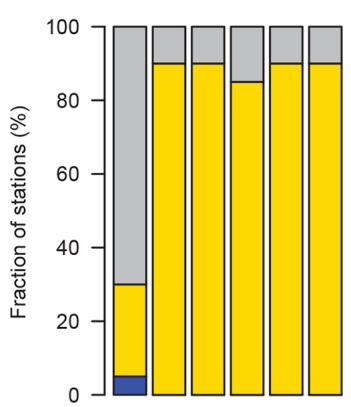

(b) $\stackrel{\circ}{\circ}$

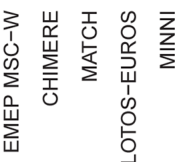

$\mathrm{TNH}_{\mathrm{x}}$ 2000-2010 (P2)

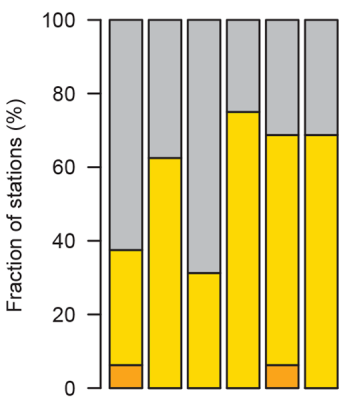

(e)

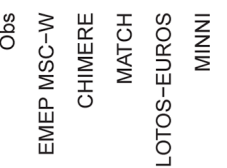

$\mathrm{TNO}_{3} 2000-2010(\mathrm{P} 2)$

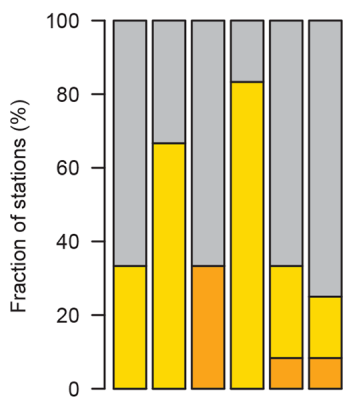

(h)
$\mathrm{SO}_{4}^{2-1990-2010}(\mathrm{PT})$

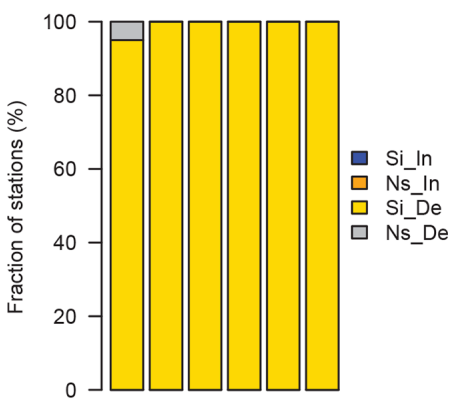

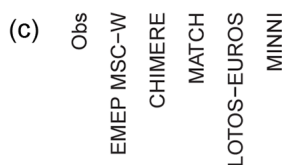

$\mathrm{TNH}_{\mathrm{x}}$ 1990-2010 (PT)
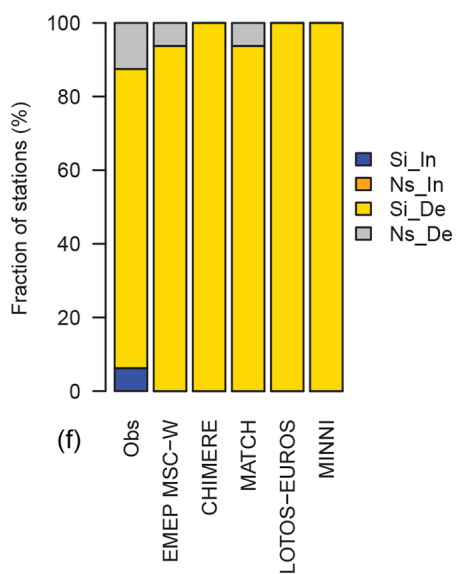

$\mathrm{TNO}_{3}$ 1990-2010 (PT)

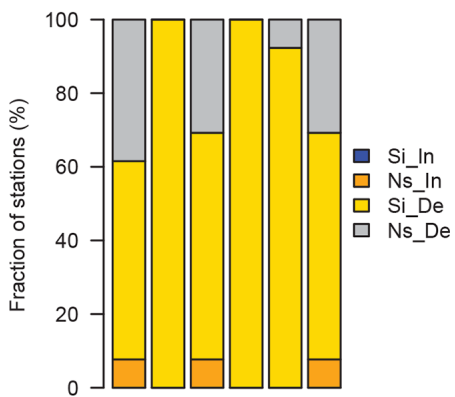

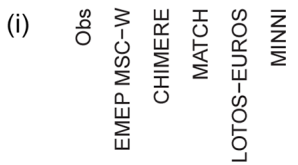

Figure 8. Percentage of statistically significant/non-significant (Si, Ns) increasing/decreasing (In, De) trends in the observations and modeled data for $\mathrm{SO}_{4}^{2-}(\mathbf{a}-\mathbf{c}), \mathrm{TNH}_{x}(\mathbf{d}-\mathbf{f})$ and $\mathrm{TNO}_{3}(\mathbf{g}-\mathbf{i})$ for the P1 (1990-2000), P2 (2000-2010) and PT (1990-2010) periods (from left to right). The number observational sites are $20,13,16$ for $\mathrm{SO}_{4}^{2-}, \mathrm{TNH}_{x}$ and $\mathrm{TNO}_{3}$, respectively. 
Table 4. Same as Table 3 but for $\mathrm{SO}_{4}^{2-}, \mathrm{TNH}_{x}$ and $\mathrm{TNO}_{3}$.

\begin{tabular}{|c|c|c|c|c|c|c|}
\hline $\mathrm{SO}_{4}^{2-}$ & P1 (\%) & $\mathrm{P} 2(\%)$ & PT (\%) & $\begin{array}{r}\text { P1 (\% of points } \\
\text { within a factor of } 2)\end{array}$ & $\begin{array}{r}\text { P2 (\% of points } \\
\text { within a factor of } 2)\end{array}$ & $\begin{array}{r}\text { PT (\% of points } \\
\text { within a factor of } 2)\end{array}$ \\
\hline Obs & -57 & -14 & -66 & - & - & - \\
\hline EMEP MSC-W & -49 & -24 & -67 & 95 & 65 & 100 \\
\hline CHIMERE & -54 & -33 & -73 & 95 & 60 & 100 \\
\hline MATCH & -47 & -28 & -67 & 95 & 65 & 100 \\
\hline LOTOS-EUROS & -42 & -23 & -61 & 95 & 65 & 100 \\
\hline MINNI & -54 & -35 & -78 & 90 & 65 & 100 \\
\hline $\mathrm{TNH}_{x}$ & P1 (\%) & $\mathrm{P} 2(\%)$ & PT (\%) & $\begin{array}{r}\text { P1 (\% of points } \\
\text { within a factor of } 2 \text { ) }\end{array}$ & $\begin{array}{r}\text { P2 (\% of points } \\
\text { within a factor of } 2)\end{array}$ & $\begin{array}{r}\text { PT (\% of points } \\
\text { within a factor of } 2)\end{array}$ \\
\hline Obs & -28 & -22 & -46 & - & - & - \\
\hline EMEP MSC-W & -15 & -14 & -27 & 44 & 75 & 75 \\
\hline CHIMERE & -23 & -14 & -31 & 44 & 75 & 75 \\
\hline MATCH & -19 & -21 & -35 & 44 & 81 & 81 \\
\hline LOTOS-EUROS & -16 & -11 & -29 & 25 & 69 & 63 \\
\hline MINNI & -26 & -13 & -38 & 56 & 81 & 75 \\
\hline $\mathrm{TNO}_{3}$ & P1 (\%) & P2 (\%) & PT (\%) & $\begin{array}{r}\text { P1 (\% of points } \\
\text { within a factor of } 2)\end{array}$ & $\begin{array}{r}\mathrm{P} 2(\% \text { of points } \\
\text { within a factor of } 2)\end{array}$ & $\begin{array}{r}\text { PT (\% of points } \\
\text { within a factor of } 2)\end{array}$ \\
\hline Obs & -16 & -19 & -29 & - & - & - \\
\hline EMEP MSC-W & -18 & -25 & -38 & 62 & 85 & 54 \\
\hline CHIMERE & -17 & -8 & -28 & 46 & 38 & 54 \\
\hline MATCH & -18 & -27 & -39 & 46 & 77 & 54 \\
\hline LOTOS-EUROS & -19 & -17 & -37 & 46 & 54 & 54 \\
\hline MINNI & -16 & -14 & -28 & 31 & 54 & 54 \\
\hline
\end{tabular}

and PT periods (Fig. 7 and Table 4). The percentage of statistically significant/non-significant increasing/decreasing observed and modeled $\mathrm{TNO}_{3}$ trends revealed that most of the models were able to reproduce the large fraction of non-significant decreasing observed trends. The EMEP and MATCH models estimate a larger fraction of significant decreasing trends than the other models in both the P1 and P2 periods, where CHIMERE and MINNI show the largest fraction of non-significant decreases. CHIMERE also shows the largest fraction of non-significant increasing trends during the $\mathrm{P} 2$ period (Fig. 8).

As for the $\mathrm{SO}_{2}$ and $\mathrm{NO}_{2}$ gas-phase species, an additional trend analysis was performed using a GLS fit model. For $\mathrm{SO}_{4}^{2}, \mathrm{TNO}_{3}$ and $\mathrm{TNH}_{x}$ results were also in line with the one predicted by the Theil-Sen and Mann-Kendall methods (Fig. S3 and Table S3). For $\mathrm{SO}_{4}^{2-}$ and $\mathrm{TNO}_{3}$, the GLS model showed higher fraction of non-significant increasing trends during the $\mathrm{P} 2$ period in the observation data, whereas for $\mathrm{TNH}_{x}$ an higher fraction of non-significant decreasing trends is predicted compared to the Theil-Sen and MannKendall methods during the $\mathrm{P} 1$ period.

Model performance for $\mathrm{SO}_{4}^{2-}, \mathrm{TNO}_{3}$ and $\mathrm{TNH}_{x}$ was also satisfactory; the recommended model performance criteria (MFB $\leq \pm 60 \%, \mathrm{MFE} \leq+75 \%$ ) as well as the performance goal $(\mathrm{MFB} \leq \pm 30 \%$, MFE $\leq+50 \%$ ) proposed by Boylan and Russell (2006) were achieved in both the P1 and P2 periods by most of the models apart from $\mathrm{TNO}_{3}$ in CHIMERE during the P1 and P2 periods and in EMEP MSC-W during the P1 period, where only the model performance criteria were achieved (Fig. S4). In addition, the evolution of the MFB over the full 1990-2010 period does not indicate any substantial change in 2010 compared to the first year of the exercise (i.e., 1990) apart from $\mathrm{TNH}_{x}$ which tends to be slightly more positively biased in the latter part of the period compared to 1990 (Fig. S5).

\subsubsection{Trends in modeled $\mathrm{HNO}_{3}$ and $\mathrm{NO}_{3}^{-}$ concentrations for different subregions}

In order to further investigate the trends in $\mathrm{TNO}_{3}$ concentrations described in the previous paragraph, we also investigated the modeled trends in $\mathrm{HNO}_{3}$ and $\mathrm{NO}_{3}^{-}$concentrations (for the different subregions in Fig. 1).

Figure 9 illustrates the relative trends in $\mathrm{HNO}_{3}$ and $\mathrm{NO}_{3}^{-}$ (sum of the coarse and fine particle fractions) for the P1 (first two columns in Fig. 9) and P2 (last two columns in Fig. 9) periods, for all the models that participated in the experiment. In general, during the P1 period, the models indicate larger significant decreases in $\mathrm{HNO}_{3}$ compared with $\mathrm{NO}_{3}^{-}$, especially over the Fennoscandia and central European regions. A few differences in the spatial distribution of the modeled 

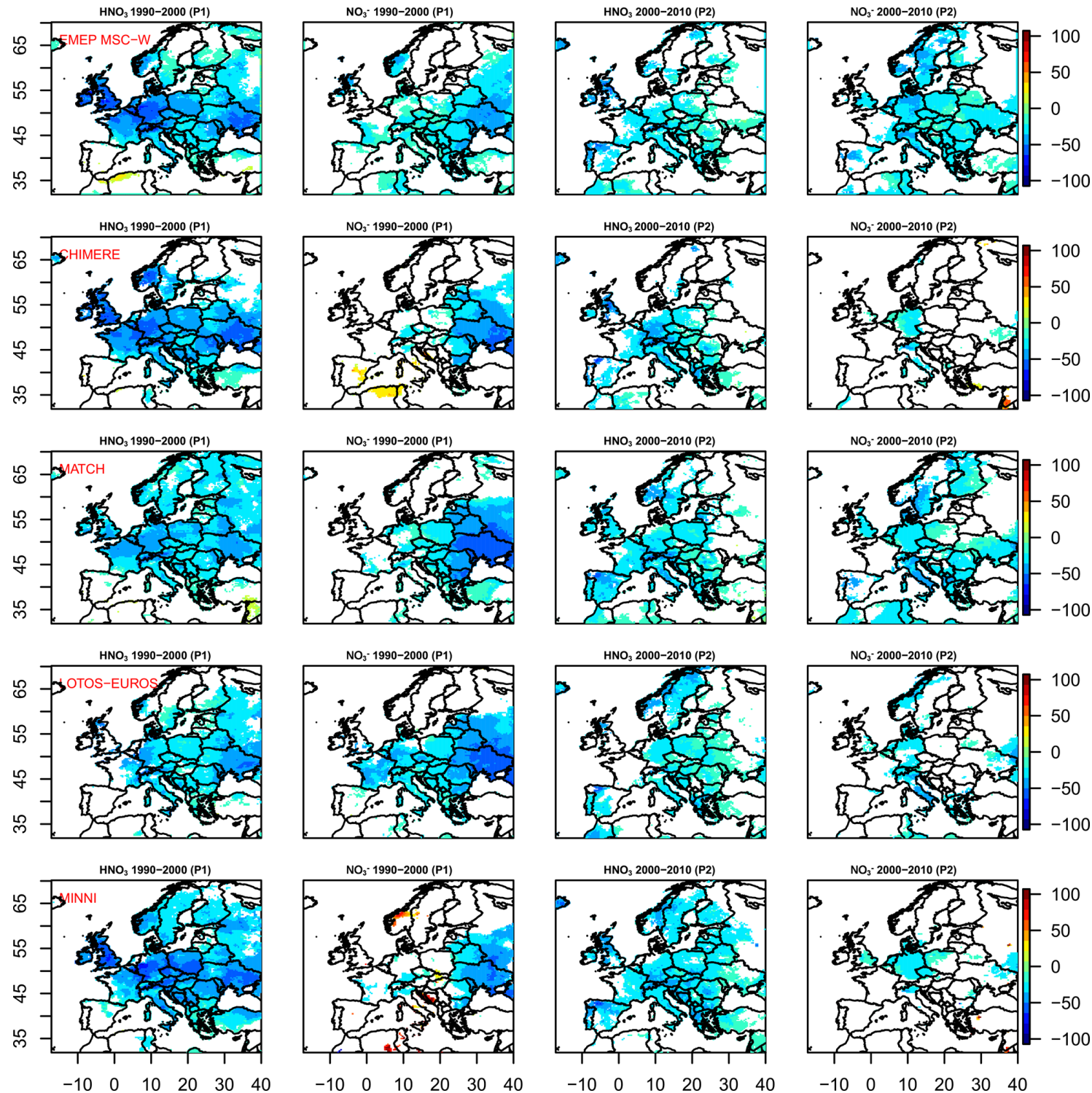

Figure 9. Modeled $\mathrm{HNO}_{3}$ and $\mathrm{NO}_{3}^{-}$relative trends over land for the P1 (1990-2000, first and second columns) and P2 (2000-2010, third and fourth columns) periods as predicted by all the models (rows; from top to bottom: EMEP MSC-W, CHIMERE, MATCH, LOTOS-EUROS, MINNI). White areas indicate non-significant trends.
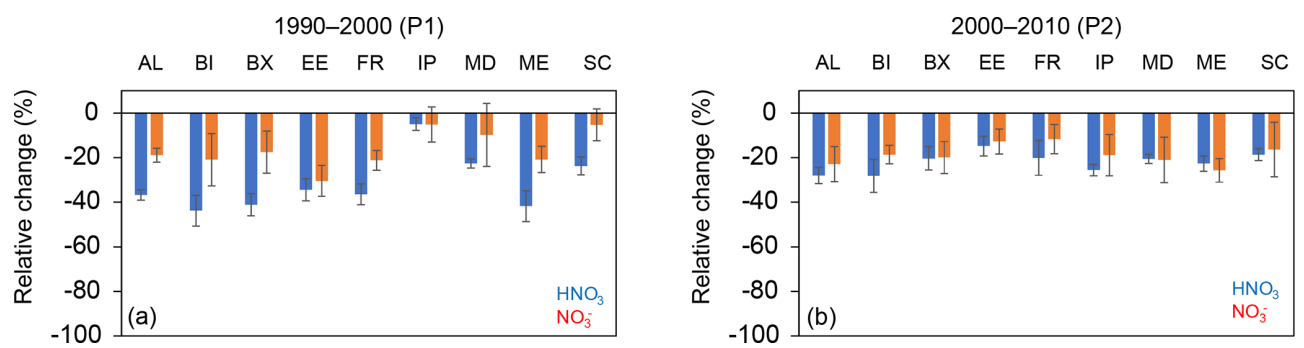

Figure 10. Modeled relative trends in $\mathrm{HNO}_{3}$ and $\mathrm{NO}_{3}^{-}$concentrations for the different PRUDENCE zones (Fig. 1) for the P1 (a) and P2 (b) periods. The columns show the averages (over land) of all the model estimates and the bars show the standard deviation with respect to the models. 
Table 5. Means and standard deviations of the modeled relative changes in $\mathrm{HNO}_{3}$ and $\mathrm{NO}_{3}^{-}$concentrations for the $\mathrm{P} 1$ (1990-2000) and $\mathrm{P} 2$ (2000-2010) periods for all the PRUDENCE regions (Fig. 1).

\begin{tabular}{|c|c|c|c|c|}
\hline \multirow[b]{2}{*}{ Regions } & \multicolumn{2}{|c|}{ 1990-2000 (P1) } & \multicolumn{2}{|c|}{ 2000-2010 (P2) } \\
\hline & $\begin{array}{r}\mathrm{HNO}_{3} \text { relative } \\
\text { change }( \pm \mathrm{SD})(\%)\end{array}$ & $\begin{array}{r}\mathrm{NO}_{3}^{-} \text {relative } \\
\text { change }( \pm \mathrm{SD})(\%)\end{array}$ & $\begin{array}{r}\mathrm{HNO}_{3} \text { relative } \\
\text { change }( \pm \mathrm{SD})(\%)\end{array}$ & $\begin{array}{r}\mathrm{NO}_{3}^{-} \text {relative } \\
\text { change }( \pm \mathrm{SD})(\%)\end{array}$ \\
\hline $\mathrm{AL}$ & $-37( \pm 2)$ & $-19( \pm 3)$ & $-28( \pm 4)$ & $-23( \pm 8)$ \\
\hline BI & $-44( \pm 7)$ & $-21( \pm 12)$ & $-28( \pm 7)$ & $-19( \pm 4)$ \\
\hline $\mathrm{BX}$ & $-41( \pm 5)$ & $-18( \pm 9)$ & $-20( \pm 5)$ & $-20( \pm 7)$ \\
\hline $\mathrm{EE}$ & $-34( \pm 5)$ & $-30( \pm 7)$ & $-15( \pm 4)$ & $-13( \pm 6)$ \\
\hline FR & $-36( \pm 5)$ & $-21( \pm 4)$ & $-20( \pm 8)$ & $-12( \pm 7)$ \\
\hline IP & $-5( \pm 3)$ & $-5( \pm 8)$ & $-26( \pm 3)$ & $-19( \pm 9)$ \\
\hline MD & $-23( \pm 2)$ & $-10( \pm 14)$ & $-21( \pm 2)$ & $-21( \pm 10)$ \\
\hline $\mathrm{ME}$ & $-42( \pm 7)$ & $-21( \pm 6)$ & $-23( \pm 3)$ & $-26( \pm 5)$ \\
\hline $\mathrm{SC}$ & $-24( \pm 4)$ & $-5( \pm 7)$ & $-19( \pm 3)$ & $-16( \pm 12)$ \\
\hline
\end{tabular}

$\mathrm{HNO}_{3}$ and $\mathrm{NO}_{3}^{-}$trends can be seen in Fig. 9. For instance, for the LOTOS-EUROS model, the significant relative trends in both $\mathrm{HNO}_{3}$ and $\mathrm{NO}_{3}^{-}$concentrations are more comparable during the P1 period, whereas MINNI and CHIMERE estimate larger areas of non-significant trends in $\mathrm{NO}_{3}^{-}$concentrations, with some significant increases in a few parts of the domain. Figure 10 and Table 5 show the models' average relative changes and standard deviation (over land) of $\mathrm{HNO}_{3}$ and $\mathrm{NO}_{3}^{-}$for all the PRUDENCE zones for the P1 and P2 periods. During the $\mathrm{P} 1$ period, the regions classified as Alps (AL), British Isles (BI), Benelux area (BX), France (FR) and mid-Europe (ME) had the largest decrease in $\mathrm{HNO}_{3}$ concentrations, with average decreases between $36 \%$ and $44 \%$ (Table 5). A comparison of $\mathrm{HNO}_{3}$ and $\mathrm{NO}_{3}^{-}$relative trends for the same regions shows that $\mathrm{NO}_{3}^{-}$concentrations declined to a lesser extent, i.e., around $20 \%$, which is roughly half of the modeled relative reduction in $\mathrm{HNO}_{3}$ concentrations. The largest difference between the relative reduction in $\mathrm{HNO}_{3}$ and $\mathrm{NO}_{3}^{-}$concentrations occurred over the Scandinavian regions for the $\mathrm{P} 1$ period, of $24 \%$ and $5 \%$, respectively. On the other hand, the reduction of $\mathrm{HNO}_{3}$ and $\mathrm{NO}_{3}^{-}$concentrations were comparable in the eastern European region and over the Iberian Peninsula (Table 5), as well as during the $\mathrm{P} 2$ periods.

The non-linear response of $\mathrm{HNO}_{3}$ concentrations and $\mathrm{NO}_{3}^{-}$concentrations, i.e., larger relative reduction in $\mathrm{HNO}_{3}$ compared to $\mathrm{NO}_{3}^{-}$, could be attributed to the shift in the thermodynamic equilibrium of $\mathrm{HNO}_{3}$ versus particle nitrate $\mathrm{NO}_{3}^{-}$. In fact, for specific regions and especially during the $\mathrm{P} 1$ period, the large reduction in $\mathrm{SO}_{2}$ emissions increased the availability of "free ammonia" and thus the transfer of more $\mathrm{HNO}_{3}$ into the particle phase, favoring the formation of ammonium nitrate. This also increases the $\mathrm{TNO}_{3}$ lifetime as dry deposition is much more rapid for $\mathrm{HNO}_{3}$ than for $\mathrm{NO}_{3}^{-}$. This effect could contribute to the reduced $\mathrm{TNO}_{3}$ decreases with respect to the $\mathrm{NO}_{2}$ decrease. Figure 11 shows the modeled $\mathrm{HNO}_{3} / \mathrm{NO}_{3}^{-}$and $\mathrm{NH}_{3} / \mathrm{NH}_{4}^{+}$molar ratio for the $\mathrm{P} 1$ and $\mathrm{P} 2$ periods, as predicted by all the models. In general, the mod- els indicate significant decreasing trends in the $\mathrm{HNO}_{3} / \mathrm{NO}_{3}^{-}$ ratio especially over Scandinavian regions (to a lesser extent in the LOTOS-EUROS model) and a strong increase in the $\mathrm{NH}_{3} / \mathrm{NH}_{4}^{+}$ratio over the whole domain except for some eastern European areas.

\subsubsection{Trends in modeled $\mathrm{SO}_{4}^{2-}$ and $\mathrm{SO}_{2}$ concentrations for different subregions}

In this section, the trends in modeled $\mathrm{SO}_{4}^{2-}$ and $\mathrm{SO}_{2}$ for the subregions reported in Fig. 1 are discussed. Figure 12 illustrates the relative trends in $\mathrm{SO}_{2}$ and $\mathrm{SO}_{4}^{2-}$ concentrations for the P1 (first two columns) and P2 (last two columns) periods for all the models that participated in the experiment. Trends were predicted to be statistically significant over the whole domain during the $\mathrm{P} 1$ period and to a lesser extent over eastern and northern European regions during the P2 period. A larger decline in $\mathrm{SO}_{2}$ concentrations during the $\mathrm{P} 1$ period was predicted in the mid-Europe areas, around $85 \%$ relative reductions, compared to the Iberian Peninsula, Mediterranean and Fennoscandia areas (average reduction $24 \%, 48 \%$ and $33 \%$, respectively) (Fig. 12 and Table 6). During the $\mathrm{P} 2$ period, the modeled relative reductions of $\mathrm{SO}_{2}$ were in the range $33 \%-65 \%$, with the Iberian Peninsula showing a larger reduction compared to the $\mathrm{P} 1$ period. As already discussed in the evaluation section, $\mathrm{SO}_{4}^{2-}$ declined to a lesser degree than $\mathrm{SO}_{2}$, by $34 \%$ and $59 \%$ in the $\mathrm{P} 1$ period and $30 \%-49 \%$ in the $\mathrm{P} 2$ period, likely because of the increased availability of oxidant species and $\mathrm{pH}$-dependent cloud chemistry.

\subsection{Trends in organic species}

\subsubsection{SOA evaluation}

During the P2 period, various field campaigns were performed in Europe using AMS instruments to measure ambient $\mathrm{OA}$ concentrations at various sites. Using factor-analysis 

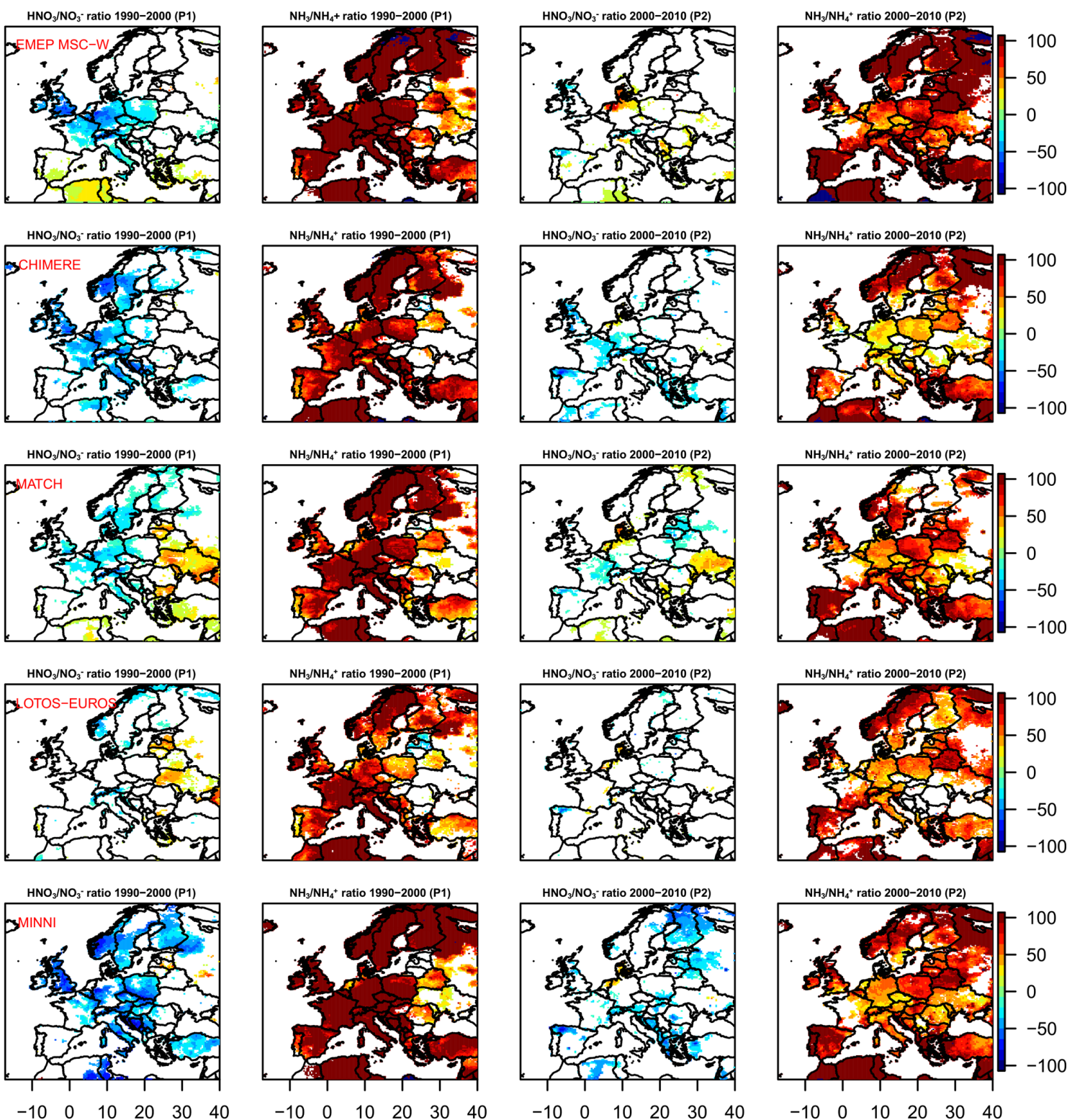

Figure 11. Modeled $\mathrm{HNO}_{3} / \mathrm{NO}_{3}^{-}$and $\mathrm{NH}_{3} / \mathrm{NH}_{4}^{+}$molar ratio relative trends over land for the $\mathrm{P} 1$ (1990-2000, first and second columns) and P2 (2000-2010, third and fourth columns) periods as predicted by all the models (rows; from top to bottom: EMEP MSC-W, CHIMERE, MATCH, LOTOS-EUROS, MINNI). White areas indicate non-significant trends. The scale was saturated at $100 \%$ to facilitate the comprehension of the panels.

techniques, i.e., PMF, it was possible to apportion the measured OA to a direct emitted organic factor, i.e., POA, and a more oxidized secondary factor, referred to as SOA. Even though this methodology is affected by various sources of uncertainties, we used this dataset to provide a general benchmark for modeled SOA performance during the P2 period.

Figure 14 shows the average modeled and observed SOA concentrations (retrieved from PMF analysis) for all the sites included in the analysis (Table S2 and Fig. S1), as well as for campaigns carried out during winter and summer periods (astronomical seasons). All the models underesti- mate observed SOA concentrations, in general, with larger variabilities between models than for the secondary inorganic species (Sect. 3.2.2). On average, the models underestimated the SOA concentrations by about a factor of 3 to 11 (Table 7, Appendix A), depending on the specific model (MATCH underestimating the most and EMEP MSC$\mathrm{W}$ the least) and with a larger underestimation during winter periods. The EMEP MSC-W model, which accounts for aging of SOA, was closer to the observations, with average SOA concentrations of about $0.7 \mu \mathrm{g} \mathrm{m}^{-3}$. The higher SOA mass modeled by the EMEP MSC-W model could be 

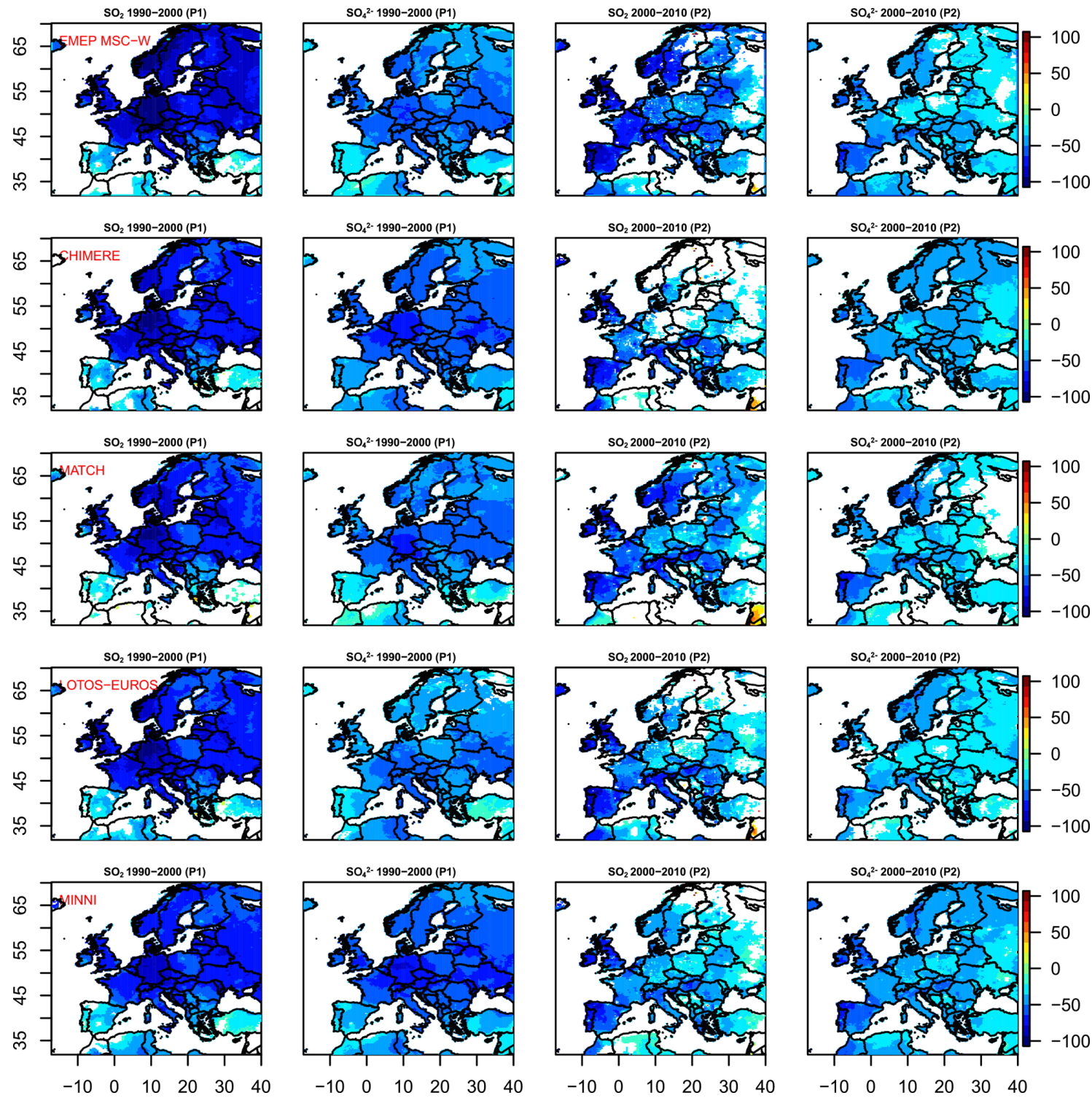

Figure 12. Modeled $\mathrm{SO}_{2}$ and $\mathrm{SO}_{4}^{2-}$ relative trends over land for the $\mathrm{P} 1$ (1990-2000, first and second columns) and P2 (2000-2010, third and fourth columns) periods as predicted by all the models (rows; from top to bottom: EMEP MSC-W, CHIMERE, MATCH, LOTOS-EUROS, MINNI). White areas indicate non-significant trends. The scale was saturated at $100 \%$ to facilitate the comprehension of the panels.
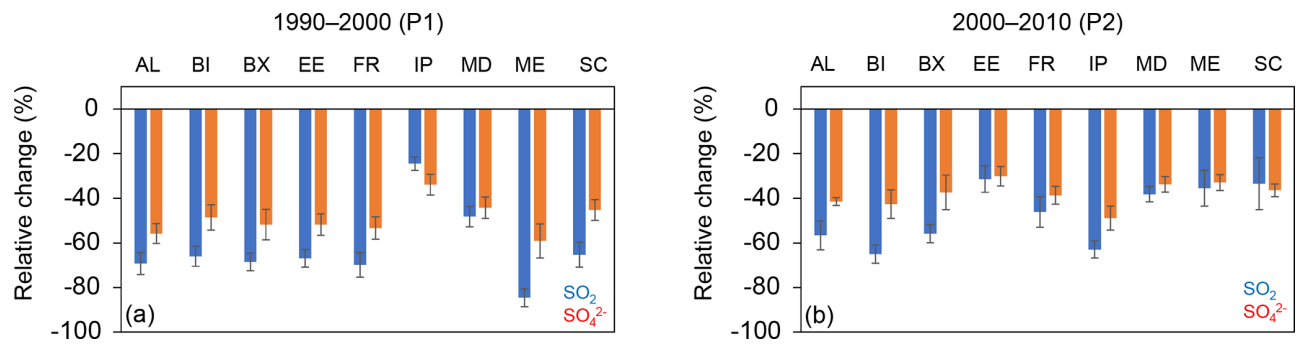

Figure 13. Modeled relative trends in $\mathrm{SO}_{2}$ and $\mathrm{SO}_{4}^{2-}$ concentrations for the different PRUDENCE zones (Fig. 1) for the P1 (a) and P2 (b) periods. The columns show the averages (over land) of all the model estimates and the bars show the standard deviation with respect to the models. 
Table 6. Means and standard deviations of the modeled relative changes in $\mathrm{SO}_{2}$ and $\mathrm{SO}_{4}^{2-}$ concentrations for the $\mathrm{P} 1$ (1990-2000) and $\mathrm{P} 2$ (2000-2010) periods for all the PRUDENCE regions (Fig. 1).

\begin{tabular}{lrr|rr}
\hline & \multicolumn{2}{c|}{$1990-2000(\mathrm{P} 1)$} & \multicolumn{2}{c}{$2000-2010(\mathrm{P} 2)$} \\
\cline { 2 - 4 } Regions & $\begin{array}{r}\mathrm{SO}_{2} \text { relative } \\
\text { change }( \pm \mathrm{SD})(\%)\end{array}$ & $\begin{array}{r}\mathrm{SO}_{4}^{2-} \text { relative } \\
\text { change }( \pm \mathrm{SD})(\%)\end{array}$ & $\begin{array}{r}\mathrm{SO}_{2} \text { relative } \\
\text { change }( \pm \mathrm{SD})(\%)\end{array}$ & $\begin{array}{r}\mathrm{SO}_{4}^{2-} \text { relative } \\
\text { change }( \pm \mathrm{SD})(\%)\end{array}$ \\
\hline $\mathrm{AL}$ & $-69( \pm 5)$ & $-56( \pm 4)$ & $-57( \pm 7)$ & $-41( \pm 2)$ \\
$\mathrm{BI}$ & $-66( \pm 4)$ & $-49( \pm 6)$ & $-65( \pm 4)$ & $-43( \pm 6)$ \\
$\mathrm{BX}$ & $-69( \pm 4)$ & $-52( \pm 9)$ & $-56( \pm 4)$ & $-37( \pm 8)$ \\
$\mathrm{EE}$ & $-67( \pm 4)$ & $-52( \pm 5)$ & $-31( \pm 6)$ & $-30( \pm 4)$ \\
$\mathrm{FR}$ & $-70( \pm 6)$ & $-53( \pm 5)$ & $-46( \pm 7)$ & $-39( \pm 4)$ \\
$\mathrm{IP}$ & $-24( \pm 3)$ & $-34( \pm 5)$ & $-63( \pm 4)$ & $-49( \pm 5)$ \\
$\mathrm{MD}$ & $-48( \pm 5)$ & $-44( \pm 5)$ & $-38( \pm 3)$ & $-34( \pm 3)$ \\
$\mathrm{ME}$ & $-85( \pm 4)$ & $-59( \pm 8)$ & $-35( \pm 8)$ & $-33( \pm 4)$ \\
$\mathrm{SC}$ & $-65( \pm 6)$ & $-45( \pm 5)$ & $-33( \pm 12)$ & $-36( \pm 3)$ \\
\hline
\end{tabular}

Table 7. Observed and predicted SOA concentrations, averaged over all sites (Table S2 and Fig. S1), and for the summer and winter campaigns. Statistics are normalized mean bias (NMB), normalized mean error (NME), mean bias (MB) and mean absolute gross error (MAGE).

\begin{tabular}{llrrrrrr}
\hline & & $\begin{array}{r}\text { Mean predicted } \\
\left(\mu \mathrm{g} \mathrm{m}^{-3}\right)\end{array}$ & $\begin{array}{r}\text { Mean observed } \\
\left(\mu \mathrm{g} \mathrm{m}^{-3}\right)\end{array}$ & $\begin{array}{r}\text { NMB } \\
(\%)\end{array}$ & $\begin{array}{r}\text { NME } \\
(\%)\end{array}$ & $\begin{array}{r}\text { MB } \\
\left(\mu \mathrm{g} \mathrm{m}^{-3}\right)\end{array}$ & $\begin{array}{r}\text { MAGE } \\
\left(\mu \mathrm{g} \mathrm{m}^{-3}\right)\end{array}$ \\
\hline \multirow{2}{*}{ Winter } & EMEP MSC-W & 0.21 & 1.98 & -0.90 & 0.90 & -1.78 & 1.78 \\
& CHIMERE & 0.12 & 1.98 & -0.94 & 0.94 & -1.87 & 1.87 \\
& MATCH & 0.12 & 1.98 & -0.94 & 0.94 & -1.86 & 1.86 \\
& MINNI & 0.29 & 1.98 & -0.85 & 0.85 & -1.69 & 1.69 \\
\hline \multirow{2}{*}{ Summer } & EMEP MSC-W & 1.42 & 2.29 & -0.38 & 0.44 & -0.87 & 1.00 \\
& CHIMERE & 0.85 & 2.29 & -0.63 & 0.63 & -1.43 & 1.43 \\
& MATCH & 0.25 & 2.29 & -0.89 & 0.89 & -2.04 & 2.04 \\
& MINNI & 0.52 & 2.29 & -0.77 & 0.77 & -1.76 & 1.76 \\
\hline \multirow{2}{*}{ All periods } & EMEP MSC-W & 0.72 & 2.03 & -0.65 & 0.73 & -1.31 & 1.48 \\
& CHIMERE & 0.39 & 2.03 & -0.81 & 0.84 & -1.64 & 1.70 \\
& MATCH & 0.18 & 2.03 & -0.91 & 0.91 & -1.85 & 1.85 \\
& MINNI & 0.57 & 2.03 & -0.72 & 0.79 & -1.46 & 1.60 \\
\hline
\end{tabular}

explained by the shift of relatively high-volatility organic compounds toward lower-volatility ranges when aging processes are accounted for (with a reaction rate toward $\mathrm{OH}$ of $4.0 \times 10^{-12} \mathrm{~cm}^{3}$ molecule $\mathrm{s}^{-1}$ in the case of the EMEP MSC-W model for both anthropogenic secondary organic aerosol (ASOA) and biogenic secondary organic aerosol (BSOA)). Such processes will increase the SOA mass since low-volatility oxidation products will rapidly condense into the particle phase. Interestingly, the MATCH model which used the same VBS scheme as the EMEP MSC-W model but without considering SOA aging processes tends to underestimate SOA concentrations substantially (Fig. 14). This indicates the importance of these chemical mechanisms in CTMs and their impact on SOA formation. On the other hand, the models based on the two-product scheme and molecular surrogate approach scheme, i.e., MINNI and CHIMERE, respectively, yielded very similar results for the total SOA mass, with SOA concentrations ranging in between the two
VBS models (i.e., around 0.4 and $0.6 \mu \mathrm{g} \mathrm{m}^{-3}$, averaged over all sites).

Figures S6 and S7 illustrate the modeled and observed (retrieved with PMF analysis) SOA concentrations at the individual sites for winter and summer periods. In general, the models had difficulties in reproducing the SOA concentrations at specific urban sites, such as Paris and Manchester (in both summer and winter periods), and in reproducing high levels of SOA concentrations at a few specific sites, e.g., Payerne, where emissions from biomass burning are high. This could be due to missing aerosol precursors (SVOC emissions) in the resident-heating sectors, which have been shown to have high uncertainties (Denier van der Gon et al., 2015).

Figure 15 shows the modeled relative and absolute contributions of anthropogenic and biogenic secondary organic aerosols to SOA concentrations. For most of the models, larger contributions of ASOA to SOA were estimated during winter periods and/or in urban areas (e.g., in Paris, Manch- 

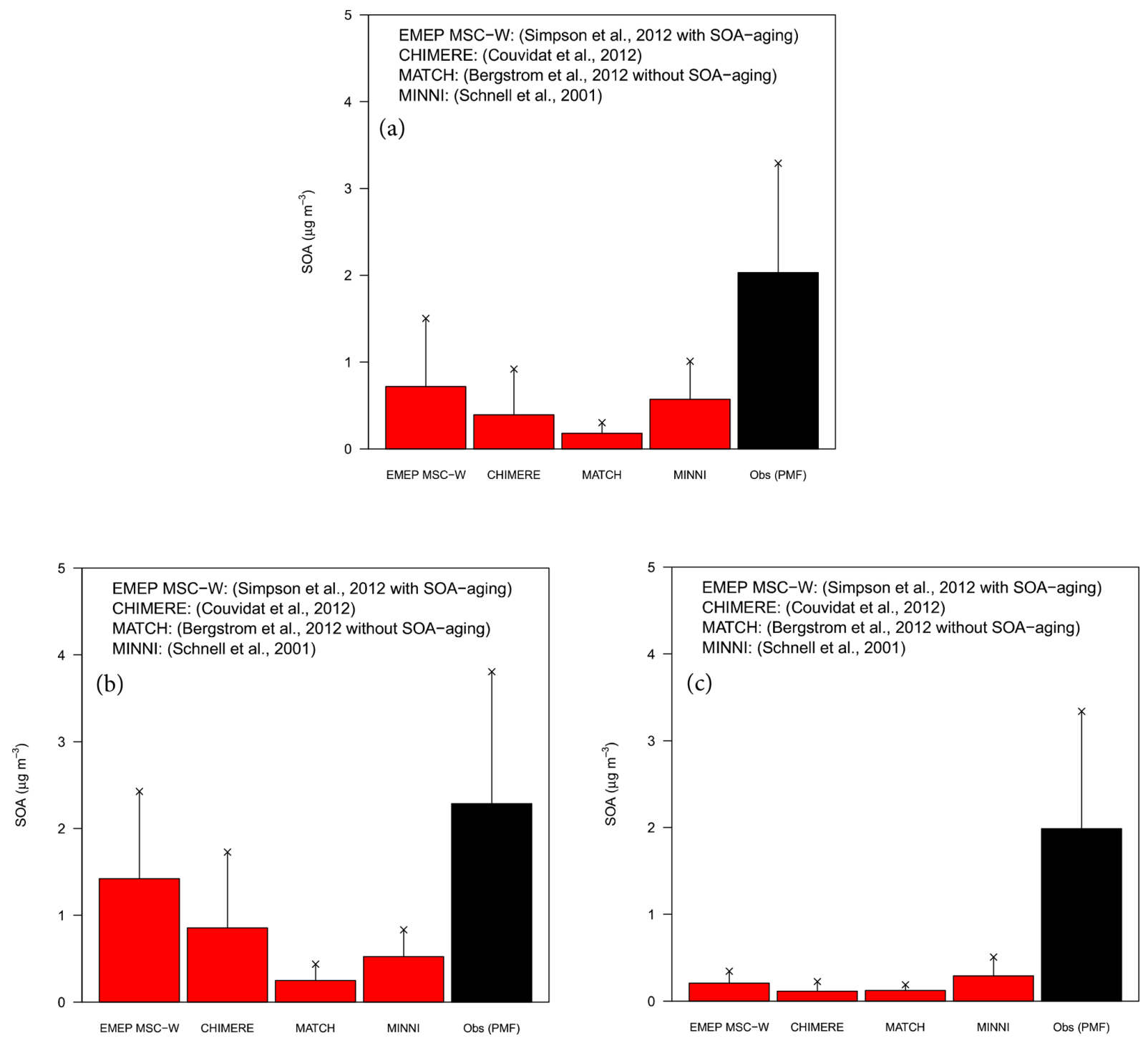

Figure 14. Modeled and observed (retrieved from PMF analysis) means and standard deviations of SOA concentrations for all periods (a), for summer campaigns (b) and winter campaigns (c) (Table S2).

ester and Payerne), whereas the BSOA contribution to SOA was largest during warmer periods. Especially in summer, large emissions of biogenic volatile organic compounds can act as an important source of SOA. The CHIMERE model simulated the largest contribution of BSOA, with only minor variations between the stations and periods.

\subsubsection{Trends in BVOCs emissions and SOA concentrations}

In this section, the trends in BVOCs emissions, i.e., isoprene and terpenes, are presented together with the trends in BSOA and ASOA concentrations. The trend analysis for BSOA and ASOA is reported for the full 1990-2010 period, for the different PRUDENCE zones and with the methodology as defined in Sect. 2.3.4. Note that not all the participants provided biogenic emissions for the full 21-year period, and only the EMEP MSC-W, CHIMERE and MATCH models provided year-by-year emissions of isoprene and monoterpenes for the EDT experiments. Moreover, for the EDT setup, CHIMERE does not include biogenic emissions for latitudes north of $65^{\circ} \mathrm{N}$.

Figures 16 and 17 illustrate the trends in isoprene and monoterpenes (first two columns) for the full 1990-2010 period. An increase in both isoprene and monoterpene species was found especially over eastern Europe (EE), with relative increases of a $15 \%-27 \%$ for isoprene and $14 \%-18 \%$ for monoterpenes, and over the Fennoscandia (SC) regions, with relative increases of $12 \%-24 \%$ in isoprene emissions and $7 \%-17 \%$ in monoterpene emissions, depending on the model (Figs. 16 and 17). Interestingly, the increase in bio- 

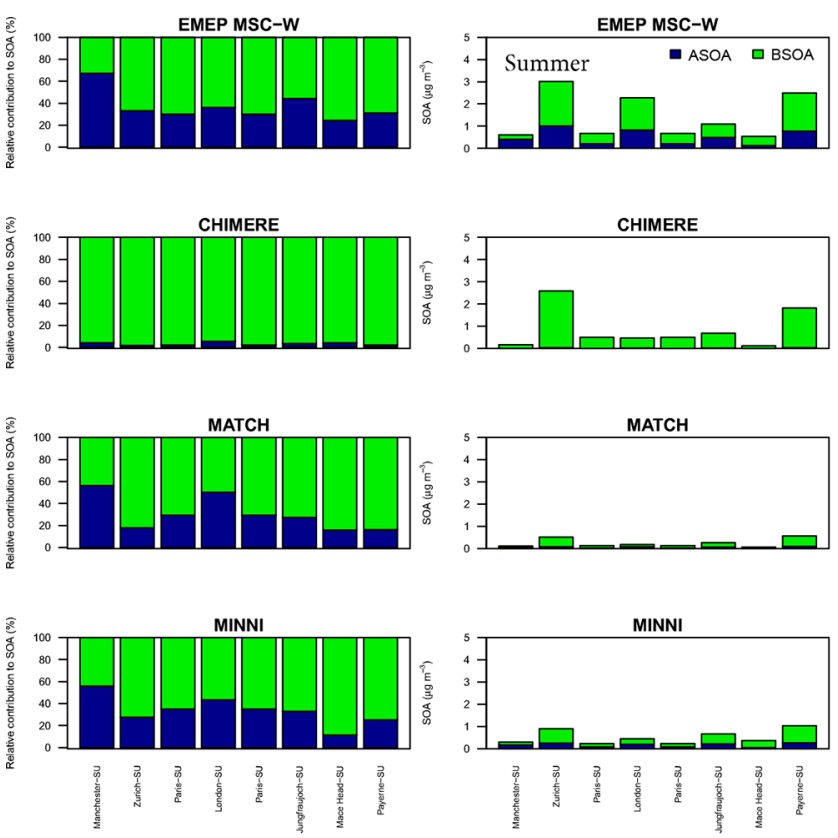
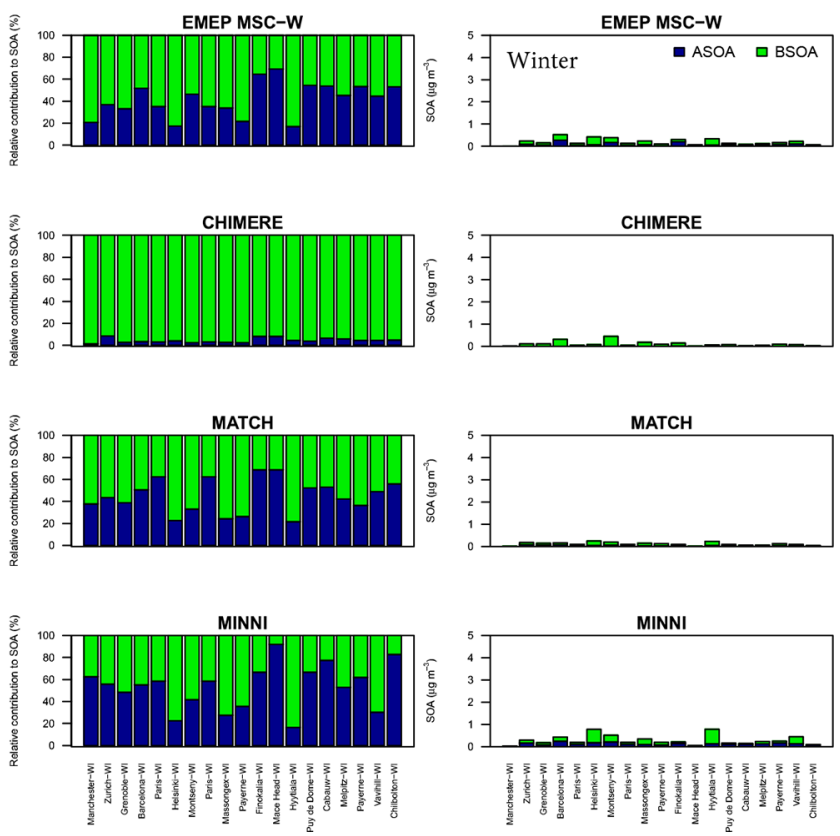

Figure 15. Modeled relative and absolute ASOA and BSOA fractions for summer (left panels) and winter (right panels) for different years (between 2000 and 2010) and seasons of the year (Table S2).

genic emissions was predicted by all biogenic models (i.e., MEGANv2.1 and the one using vegetation data from Koeble and Seufert, 2001). These increases were mainly attributed to the increase in surface temperature used to drive the different biogenic models (Fig. S8), which however were found to be not significant. The increase in surface temperature was found to be larger over Fennoscandia, Mediterranean and eastern European areas compared to the remaining zones (i.e., increases around $0.02,0.02$ and $0.03 \mathrm{~K} \mathrm{yr}^{-1}$, respectively). We want to underline that the surface solar radiation (SSR) could also play an important role for the emission of biogenic precursors (especially for isoprene). The strong reduction in $\mathrm{SO}_{4}^{2-}$ concentrations described in Sect. 3.2.2, especially in the eastern regions of the domain, might have induced an increase in the incoming solar radiation, referred to as brightening periods (Wild, 2009), which could affect the emission of biogenic species. However, none of the models that participated in the exercise have explicitly accounted for such an interaction and the ERA-Interim forcing data rely mainly on climatological aerosol profiles. On the other hand, recent sensitivity studies performed in Europe showed that such effects might be relatively small (Oikonomakis et al., 2018). Figures 16 and 17 also show the relative trends in BSOA and ASOA concentrations for all the models that were able to provide 21 years of data. Even though some models indicated few increases in the biogenic SOA concentrations over the Fennoscandia regions, these increases were found to be smaller than the increase in biogenic emissions, and in some cases, biogenic SOA concentrations were also estimated to have declined (Figs. 16 and 17). This might sound counterintuitive, since one would expect more biogenic SOA to be produced as more biogenic precursors are available and, in general, the increased availability of $\mathrm{OH}$ radicals due to the reduction in $\mathrm{NO}_{x}$ and $\mathrm{SO}_{x}$ emissions, thus increasing the oxidation efficiency of biogenic SOA precursors, especially for isoprene. A possible explanation for this non-linear relation between the trends in biogenic emissions and the trends in BSOA concentrations could be due to the trends in the anthropogenic OA concentrations. As shown in Figs. 16 and 17, a strong decrease in the ASOA concentrations was found for the entire 1990-2010 period, in line with the reduction in the NMVOC precursors described in Sect. 3.1 (mainly from transportation sectors). Modeled ASOA concentrations indicate a decline of about $60 \%-70 \%$ over the whole domain (considering only land areas). This might have had on effect on the formation of the BSOA fraction; in fact, the strong reduction in ASOA concentrations, and other aerosol organic and inorganic components, will reduce the availability of organic and inorganic material onto which the low-volatility oxidized compounds can condense, directly affecting the formation of the BSOA fraction. Additionally, oxidant levels and thus oxidation pathways could have changed over time, affecting as said before $\mathrm{OH}$ but also $\mathrm{NO}_{3}$ concentrations.

\section{Conclusions}

A modeling experiment to evaluate the capability of several chemical transport models (CTMs) to reproduce longterm air quality trends in Europe was initiated within the EURODELTA-Trends (EDT) exercise. 

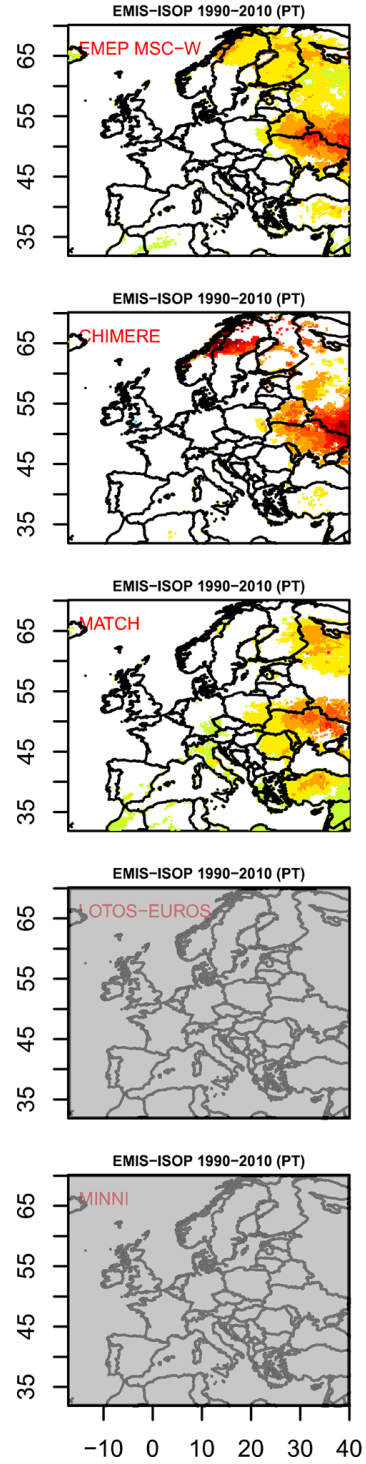
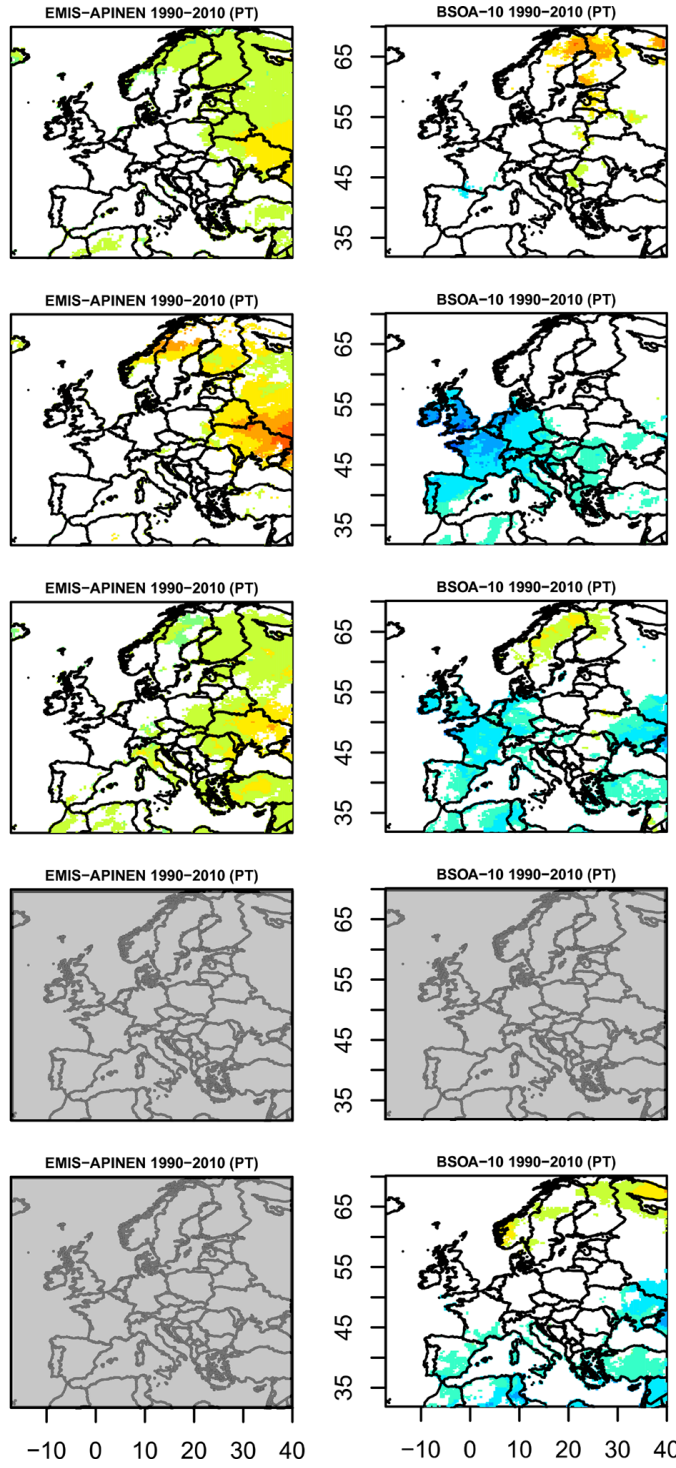
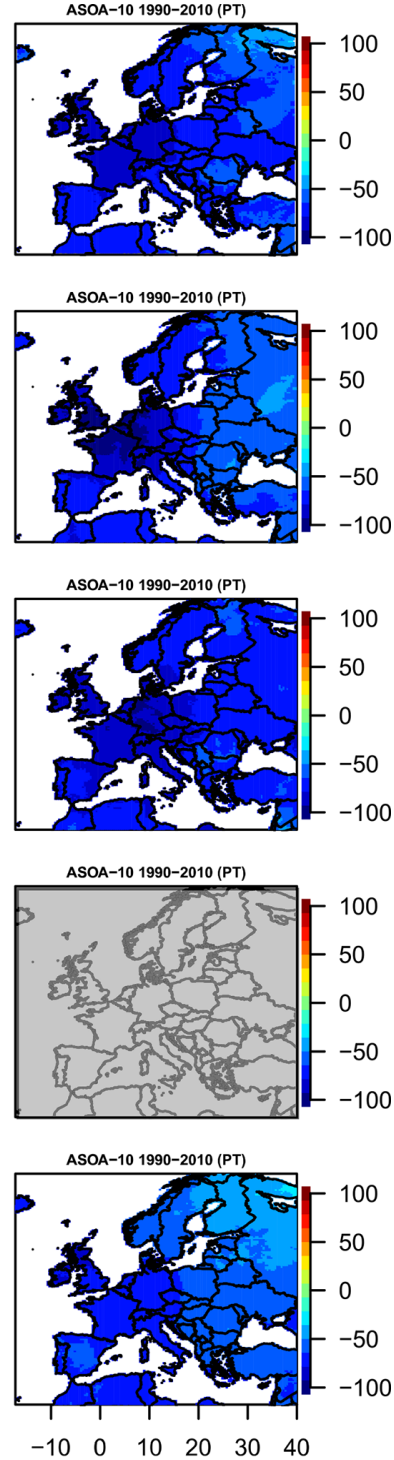

Figure 16. Modeled relative trends in isoprene and monoterpene emissions for the PT period (1990-2010, first and second columns) and biogenic and anthropogenic SOA relative trends for the PT period (1990-2010, third and fourth columns) as predicted by all the models (rows; from top to bottom: EMEP MSC-W, CHIMERE, MATCH, LOTOS-EUROS, MINNI). White areas indicate non-significant trends. Scale was saturated at $100 \%$ to facilitate the comprehension of the panel. Grey panels indicate missing data.
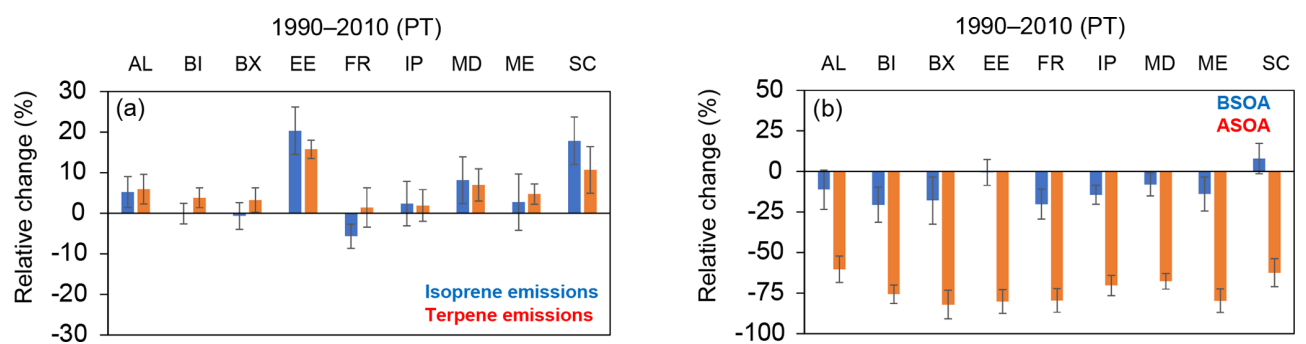

Figure 17. Modeled relative trends for the biogenic emissions (isoprene and terpene, a) and anthropogenic and biogenic SOA concentrations (b) for the different PRUDENCE zones (Fig. 1) for the 1990-2010 (PT) period. The columns show the averages (over land) of all the model estimates and the bars show the standard deviation with respect to the models. 
Common spatial resolution, anthropogenic emissions, meteorological input data and boundary conditions were used by the participants, whereas the chemical and physical parameters varied between the models. Modeled air quality data for the 1990-2010 period was evaluated against qualitycontrolled long-term measurements with a focus on several primary and secondary inorganic and organic pollutants.

In general, the experiment revealed that the models were able to reproduce the observed trends in gas-phase precursors relatively well (i.e., $\mathrm{SO}_{2}$ and $\mathrm{NO}_{2}$ ), as well as secondary inorganic species, i.e., sulfate $\left(\mathrm{SO}_{4}^{2-}\right)$, total nitrate $\left(\mathrm{TNO}_{3}\right)$ and total ammonium $\left(\mathrm{TNH}_{x}\right)$, with a few exceptions at some specific sites. The range of modeled trends over 1990-2010 encompasses the observed ones for $\mathrm{SO}_{2}, \mathrm{SO}_{4}^{2-}$ and $\mathrm{TNO}_{3}$ but not for $\mathrm{TNH}_{x}$ and $\mathrm{NO}_{2}$. The modeled relative declines of $\mathrm{NO}_{2}$ concentrations were found to be $19 \%-23 \%$ during the 1990-2000 period (P1) and 22\%-26\% during the 2000-2010 period (P2), depending on the model. These values were in line with the relative trends calculated from the observations, around $25 \%$ and $12 \%$, for the $\mathrm{P} 1$ and $\mathrm{P} 2$ periods, respectively (mean values of all sites), even if models did not catch the observed stronger decrease in P1 and weaker decrease in $\mathrm{P} 2$. Their difficulty in reproducing the weaker decline over the second period is attributed to the challenge in modeling low $\mathrm{NO}_{2}$ levels at EMEP background sites during that period.

The large decline in $\mathrm{SO}_{2}$ and $\mathrm{SO}_{4}^{2-}$ concentrations during the early 1990s, due to the switch to low-sulfur fuels (e.g., natural gas) and the adoption of desulfurization technologies, was well reproduced by the models, with most of the absolute trends in observations being reproduced within a factor of 2 . As expected, $\mathrm{SO}_{2}$ decreases faster than $\mathrm{SO}_{x}$ emissions, and $\mathrm{SO}_{4}^{2-}$ decreases less. This is due to the increase in cloud $\mathrm{pH}$ that accelerates in-cloud sulfur chemistry that consumes $\mathrm{SO}_{2}$ to form $\mathrm{SO}_{4}^{2-}$, constituting a positive retroaction for $\mathrm{SO}_{2}$ decrease and a negative retroaction for $\mathrm{SO}_{4}^{2-}$. This effect was well reproduced by the models.

$\mathrm{TNH}_{x}$ decreases much faster than $\mathrm{NH}_{3}$ emissions (respectively, $46 \%$ and $15 \%$ over 1990-2010). This is due to a change of $\mathrm{TNH}_{x}$ partitioning, which shifts towards gas when the atmospheric load of acids $\left(\mathrm{H}_{2} \mathrm{SO}_{4}\right.$ and $\left.\mathrm{HNO}_{3}\right)$ decrease. Consequently, a larger fraction of $\mathrm{TNH}_{x}$ is in $\mathrm{NH}_{3}$ form, which deposits faster than $\mathrm{NH}_{4}^{+}$, leading to a positive retroaction in enhancing the downward trend of $\mathrm{TNH}_{x}$. Deposition plays a critical role in $\mathrm{TNH}_{x}$ trends, and it has been noted that the observed decrease in wet deposition in the 1990s was largely driven by a couple of monitoring stations that experienced a sharp drop between 1995 and 1996 (Theobald et al., 2019) which the models fail to capture.

The trends in $\mathrm{TNH}_{x}$ concentrations were thus underestimated, especially during the first decade (1990-2000), with the models exhibiting larger discrepancies compared to the other investigated species. Ammonia emissions certainly play an important role in the model performance for $\mathrm{TNH}_{x}$.
In fact, large uncertainties remain regarding present-day ammonia emissions and higher uncertainties are probably to be expected during the early 1990s.

The models estimated relatively lower trends in $\mathrm{TNO}_{3}$ concentrations compared to other inorganic species (during the $\mathrm{P} 1$ periods), which was also indicated by the observations. A further analysis of the modeled $\mathrm{HNO}_{3}$ and $\mathrm{NO}_{3}^{-}$ components revealed that $\mathrm{HNO}_{3}^{-}$declined more than $\mathrm{NO}_{3}^{-}$ during the 1990-2000 period. We attributed the latter to a possible shift in the thermodynamic equilibrium of $\mathrm{HNO}_{3}$ following the strong reduction in $\mathrm{SO}_{2}$ concentrations, resulting in more "free ammonia" available to drive the $\mathrm{HNO}_{3}$ into the particle phase. Such an effect was particularly enhanced over Fennoscandia regions, where differences up to a factor of 5 in the modeled relative reductions of $\mathrm{HNO}_{3}$ and $\mathrm{NO}_{3}$ concentrations were found, $24 \%$ relative reduction in $\mathrm{HNO}_{3}$ and $5 \%$ for $\mathrm{NO}_{3}^{-}$, respectively (average values of all the models for the $\mathrm{P} 1$ period). Because $\mathrm{HNO}_{3}$ deposits faster than $\mathrm{NO}_{3}^{-}$, the shift of $\mathrm{TNO}_{3}$ partitioning towards particles increases the lifetime of atmospheric nitrogen (as reported by Simpson et al., 2014), which contributes to the explaination that $\mathrm{TNO}_{3}$ decreases less than $\mathrm{NO}_{x}$ emission.

A comprehensive dataset of SOA concentrations retrieved from PMF analyses was used to investigate the models' capabilities of reproducing the SOA concentrations during the 2000-2010 period. The analysis of modeled SOA concentrations indicated that the models underestimated the SOA fraction by varying extents, by a factor of 3 to 11 , depending on the model, suggesting that large uncertainties in the SOA formation mechanisms as well as in the emissions of SOA precursors remain, and more studies are needed to better elucidate the evolution of the SOA fraction. The underestimation of the SOA fraction seemed to be more pronounced during winter periods, in line with previous studies indicating missing SOA precursors in the residential sector, one of the major contributors to SOA concentrations in Europe during winter periods. Therefore, this experiment confirmed once more the need to improve emission inventories of primary organic aerosol for the residential sector, especially regarding wood-burning emissions.

The analysis of the modeled trends in emissions of BVOCs, isoprene and monoterpenes revealed an increase in these precursor emissions during the 1990-2010 period, especially in eastern European regions and in Fennoscandia regions, by about $20 \%$. The increase was independent of the specific biogenic model used and was mainly attributed to the increase of the surface temperature during the 19902010 period. Modeled trends in ASOA concentrations indicated a strong reduction following emission reductions of non-methane volatile organic precursors, by around $60 \%$, because of the implementation of new EURO standards for passenger cars, among others. However, modeled trends in BSOA concentrations remain less clear. Despite the modeled increase in biogenic emissions, modeled BSOA concentrations showed relatively small increasing trends or even de- 
creasing trends. A possible explanation was mainly attributed to the reduction in the aerosol mass indicated by all the models. The latter could eventually reduce the condensation sink of low-volatility organic compounds and reduce the capability to form additional organic material from biogenic precursors, despite the increase in BVOCs emissions. Thus, more work is still needed to better characterize the trends in organic aerosol and especially of the BSOA fraction.

Code and data availability. Technical details of the EURODELTA project simulations that permit the replication of the experiment are available on the wiki of the EMEP Task Force on Measurement and Modelling (https://wiki.met.no/emep/emepexperts/tfmmtrendeurodelta, last access: 21 December 2018), which also includes ESGF links to corresponding input forcing data. The EURODELTA-Trends model results are made available for public use on the AeroCom server (information to gain access to the AeroCom server are available at https:/wiki.met.no/aerocom/ user-server, last access: 21 December 2018). Model input and output data are permanently stored under the /metno/aerocom-usersdatabase/EURODELTA folder on the AeroCom Server. See Colette et al. (2017) for full terms and conditions for the use of these data. Measurement data and the $\mathrm{R}$ procedures are available online at https://doi.org/10.5281/zenodo.3405386 (Ciarelli, 2019). 


\section{Appendix A}

The mean bias (MB), mean absolute gross error (MAGE), normalized mean bias (NMB), normalized mean error (NME), mean fraction bias (MFB) and mean fractional error (MFE) are used to evaluate the model performance. $M_{i}$ and $O_{i}$ stand for modeled and observed values, respectively, and $N$ is the total number of paired values.

$$
\begin{aligned}
& \text { MAGE }=\frac{1}{N} \sum_{i=1}^{N}\left|M_{i}-O_{i}\right| \\
& \mathrm{MB}=\frac{1}{N} \sum_{i=1}^{N}\left(M_{i}-O_{i}\right) \\
& \mathrm{NME}=\frac{\sum_{i=1}^{N}\left|M_{i}-O_{i}\right|}{\sum_{i=1}^{N} O_{i}} \\
& \mathrm{NMB}=\frac{\sum_{i=1}^{N}\left(M_{i}-O_{i}\right)}{\sum_{i=1}^{N} O_{i}} \\
& \mathrm{MFB}=\frac{1}{N} \sum_{i=1}^{N} \frac{2 \cdot\left(M_{i}-O_{i}\right)}{M_{i}+O_{i}} \\
& \mathrm{MFB}=\frac{1}{N} \sum_{i=1}^{N} \frac{2 \cdot\left|M_{i}-O_{i}\right|}{M_{i}+O_{i}}
\end{aligned}
$$


Supplement. The supplement related to this article is available online at: https://doi.org/10.5194/gmd-12-4923-2019-supplement.

Author contributions. ACo coordinated the EDT exercise and WA was responsible for the compilation and quality control of the observations. The following modeling teams set up, pre-processed, ran and post-processed the simulations for each model: FC, BB, MGV and ACo for CHIMERE; ST, HF and PW for EMEP; AM, MS and RK for LOTOS-EUROS; CA and RB for MATCH; MM, MA, GB, $\mathrm{ACa}$ and MD for MINNI. Additional post-processing of model output and uploading to the AeroCom server was done by KC. All of the analyses presented in this paper were carried out by GC with assistance from MT, KM, VR, YR, MTP, ACo, ACh and MB.

Competing interests. The authors declare that they have no conflict of interest.

Acknowledgements. Giancarlo Ciarelli was supported by ADEME in the framework of the MISTRALS/ChArMEx project and the Swiss National Science Foundation (grant no. P2EZP2_175166). The Ineris coordination of the EURODELTA-Trends exercise was supported by the French Ministry in charge of Ecology in the context of the Task Force on Measurement and Modelling of the EMEP program of the LRTAP Convention. Meteorological forcing with the WRF model was provided by Robert Vautard and Annemiek Stegehuis from LSCE/IPSL. The CHIMERE simulations where performed using the TGCC supercomputers under GENCI computing allocation. The participation of CIEMAT was financed by the Spanish Ministry of Agriculture and Fishing, Food and Environment. MATCH participation was partly funded by the Swedish Environmental Protection Agency through the research program Swedish Clean Air and Climate (SCAC) and partly by NordForsk through the research program Nordic WelfAir (grant no. 75007). The computing resources and the related technical support used for MINNI simulations have been provided by CRESCO/ENEAGRID highperformance computing infrastructure and its staff. The infrastructure is funded by ENEA, the Italian National Agency for New Technologies, Energy and Sustainable Economic Development and by Italian and European research programs (http://www.cresco.enea.it/ english, last access: 14 November 2019). MINNI participation to this project was supported by the "Cooperation Agreement for support to international Conventions, Protocols and related negotiations on air pollution issues", funded by the Italian Ministry for Environment and Territory and Sea. The simulations with the EMEP MSC-W model were supported by the Research Council of Norway in the framework of the Programme for Supercomputing: through the EMEP project (grant NN2890K) for CPU and the Norstore project "European Monitoring and Evaluation Programme" (grant NS9005K) for data storage. The GAINS emission trends were produced as part of the FP7 European Research Project ECLIPSE (Evaluating the Climate and Air Quality Impacts of Short-Lived Pollutants) grant no. 282688.
Financial support. This research has been supported by the Swiss National Science Foundation (grant no. P2EZP2_175166) and ADEME in the framework of a convention with laboratories within the MISTRALS/ChArMEx project (convention no. 1562C0001).

Review statement. This paper was edited by Samuel Remy and reviewed by two anonymous referees.

\section{References}

Aksoyoglu, S., Keller, J., Ciarelli, G., Prévôt, A. S. H., and Baltensperger, U.: A model study on changes of European and Swiss particulate matter, ozone and nitrogen deposition between 1990 and 2020 due to the revised Gothenburg protocol, Atmos. Chem. Phys., 14, 13081-13095, https://doi.org/10.5194/acp-14-130812014, 2014.

Amann, M., Bertok, I., Borken-Kleefeld, J., Cofala, J., Heyes, C., Höglund-Isaksson, L., Klimont, Z., Nguyen, B., Posch, M., Rafaj, P., Sandler, R., Schöpp, W., Wagner, F., and Winiwarter, W.: Cost-effective control of air quality and greenhouse gases in Europe: Modeling and policy applications, Environ. Model. Softw., 26, 1489-1501, https://doi.org/10.1016/j.envsoft.2011.07.012, 2011.

Andersson, C., Langner, J., and Bergström, R.: Interannual variation and trends in air pollution over Europe due to climate variability during 1958-2001 simulated with a regional CTM coupled to the ERA40 reanalysis, Tellus B, 59, 77-98, https://doi.org/10.1111/j.1600-0889.2006.00196.x, 2007.

Andersson, C., Bergström, R., Bennet, C., Robertson, L., Thomas, M., Korhonen, H., Lehtinen, K. E. J., and Kokkola, H.: MATCHSALSA - Multi-scale Atmospheric Transport and CHemistry model coupled to the SALSA aerosol microphysics model Part 1: Model description and evaluation, Geosci. Model Dev., 8, 171-189, https://doi.org/10.5194/gmd-8-171-2015, 2015.

Athanasiadis, I. N., Mitkas, P. A., Rizzoli, A. E., and Gómez, J. M. (Eds.): Information Technologies in Environmental Engineering: Proceedings of the 4th International ICSC Symposium Thessaloniki, Greece, 28-29 May 2009, Environmental Engineering, Springer-Verlag, Berlin Heidelberg, 2009.

Atkinson, R., Baulch, D. L., Cox, R. A., Hampson, R. F., Kerr, J. A., Rossi, M. J., and Troe, J.: Evaluated Kinetic, Photochemical and Heterogeneous Data for Atmospheric Chemistry: Supplement V. IUPAC Subcommittee on Gas Kinetic Data Evaluation for Atmospheric Chemistry, J. Phys. Chem. Ref. Data, 26, 521-1011, https://doi.org/10.1063/1.556011, 1997.

Atkinson, R., Baulch, D. L., Cox, R. A., Crowley, J. N., Hampson, R. F., Hynes, R. G., Jenkin, M. E., Rossi, M. J., and Troe, J.: Evaluated kinetic and photochemical data for atmospheric chemistry: Volume $\mathrm{I}-$ gas phase reactions of $\mathrm{O}_{x}, \mathrm{HO}_{x}$, $\mathrm{NO}_{x}$ and $\mathrm{SO}_{x}$ species, Atmos. Chem. Phys., 4, 1461-1738, https://doi.org/10.5194/acp-4-1461-2004, 2004.

Atkinson, R., Baulch, D. L., Cox, R. A., Crowley, J. N., Hampson, R. F., Hynes, R. G., Jenkin, M. E., Rossi, M. J., Troe, J., and IUPAC Subcommittee: Evaluated kinetic and photochemical data for atmospheric chemistry: Volume II - gas phase reactions of organic species, Atmos. Chem. Phys., 6, 3625-4055, https://doi.org/10.5194/acp-6-3625-2006, 2006. 
Backes, A., Aulinger, A., Bieser, J., Matthias, V., and Quante, M.: Ammonia emissions in Europe, part I: Development of a dynamical ammonia emission inventory, Atmos. Environ., 131, 55-66, https://doi.org/10.1016/j.atmosenv.2016.01.041, 2016.

Banzhaf, S., Schaap, M., Kranenburg, R., Manders, A. M. M., Segers, A. J., Visschedijk, A. J. H., Denier van der Gon, H. A. C., Kuenen, J. J. P., van Meijgaard, E., van Ulft, L. H., Cofala, J., and Builtjes, P. J. H.: Dynamic model evaluation for secondary inorganic aerosol and its precursors over Europe between 1990 and 2009, Geosci. Model Dev., 8, 1047-1070, https://doi.org/10.5194/gmd-8-1047-2015, 2015.

Bergström, R., Denier van der Gon, H. A. C., Prévôt, A. S. H., Yttri, K. E., and Simpson, D.: Modelling of organic aerosols over Europe (2002-2007) using a volatility basis set (VBS) framework: application of different assumptions regarding the formation of secondary organic aerosol, Atmos. Chem. Phys., 12, 8499-8527, https://doi.org/10.5194/acp-12-8499-2012, 2012.

Bessagnet, B., Pirovano, G., Mircea, M., Cuvelier, C., Aulinger, A., Calori, G., Ciarelli, G., Manders, A., Stern, R., Tsyro, S., García Vivanco, M., Thunis, P., Pay, M.-T., Colette, A., Couvidat, F., Meleux, F., Rouïl, L., Ung, A., Aksoyoglu, S., Baldasano, J. M., Bieser, J., Briganti, G., Cappelletti, A., D'Isidoro, M., Finardi, S., Kranenburg, R., Silibello, C., Carnevale, C., Aas, W., Dupont, J.-C., Fagerli, H., Gonzalez, L., Menut, L., Prévôt, A. S. H., Roberts, P., and White, L.: Presentation of the EURODELTA III intercomparison exercise - evaluation of the chemistry transport models' performance on criteria pollutants and joint analysis with meteorology, Atmos. Chem. Phys., 16, 12667-12701, https://doi.org/10.5194/acp-16-12667-2016, 2016.

Bian, H., Chin, M., Hauglustaine, D. A., Schulz, M., Myhre, G., Bauer, S. E., Lund, M. T., Karydis, V. A., Kucsera, T. L., Pan, X., Pozzer, A., Skeie, R. B., Steenrod, S. D., Sudo, K., Tsigaridis, K., Tsimpidi, A. P., and Tsyro, S. G.: Investigation of global particulate nitrate from the AeroCom phase III experiment, Atmos. Chem. Phys., 17, 12911-12940, https://doi.org/10.5194/acp-1712911-2017, 2017

Binkowski, F. and Shankar, U.: The Regional Particulate Matter Model: 1. Model description and preliminary results, J. Geophys. Res., 100, 26191-26209, https://doi.org/10.1029/95JD02093, 1995.

Boylan, J. W. and Russell, A. G.: PM and light extinction model performance metrics, goals, and criteria for threedimensional air quality models, Atmos. Environ., 40, 49464959, https://doi.org/10.1016/j.atmosenv.2005.09.087, 2006.

Byun, D. and Schere, K. L.: Review of the Governing Equations, Computational Algorithms, and Other Components of the Models-3 Community Multiscale Air Quality (CMAQ) Modeling System, Appl. Mech. Rev., 59, 51-77, https://doi.org/10.1115/1.2128636, 2006.

Carter, W. P. L.: Condensed atmospheric photooxidation mechanisms for isoprene, Atmos. Environ., 30, 4275-4290, https://doi.org/10.1016/1352-2310(96)00088-X, 1996.

Carter, W. P. L.: Documentation of the SAPRC-99 Chemical Mechanism for VOC Reactivity Assessment, Final Report to California Air Resources Board Contract No. 92-329, and 95-308, available at: http://www.cert.ucr.edu/ carter/absts.htm\#saprc99 (last access: 14 November 2019), 2000

Cholakian, A., Beekmann, M., Colette, A., Coll, I., Siour, G., Sciare, J., Marchand, N., Couvidat, F., Pey, J., Gros, V., Sauvage,
S., Michoud, V., Sellegri, K., Colomb, A., Sartelet, K., Langley DeWitt, H., Elser, M., Prévot, A. S. H., Szidat, S., and Dulac, F.: Simulation of fine organic aerosols in the western Mediterranean area during the ChArMEx 2013 summer campaign, Atmos. Chem. Phys., 18, 7287-7312, https://doi.org/10.5194/acp18-7287-2018, 2018.

Chrit, M., Sartelet, K., Sciare, J., Pey, J., Marchand, N., Couvidat, F., Sellegri, K., and Beekmann, M.: Modelling organic aerosol concentrations and properties during ChArMEx summer campaigns of 2012 and 2013 in the western Mediterranean region, Atmos. Chem. Phys., 17, 12509-12531, https://doi.org/10.5194/acp-17-12509-2017, 2017.

Ciarelli, G.: Procedures and observational dataset for the EDT analysis, Zenodo, https://doi.org/10.5281/zenodo.3405386, 2019.

Ciarelli, G., Aksoyoglu, S., Crippa, M., Jimenez, J.-L., Nemitz, E., Sellegri, K., Äijälä, M., Carbone, S., Mohr, C., O’Dowd, C., Poulain, L., Baltensperger, U., and Prévôt, A. S. H.: Evaluation of European air quality modelled by CAMx including the volatility basis set scheme, Atmos. Chem. Phys., 16, 10313-10332, https://doi.org/10.5194/acp-16-10313-2016, 2016.

Cohen, A. J., Brauer, M., Burnett, R., Anderson, H. R., Frostad, J., Estep, K., Balakrishnan, K., Brunekreef, B., Dandona, L., Dandona, R., Feigin, V., Freedman, G., Hubbell, B., Jobling, A., Kan, H., Knibbs, L., Liu, Y., Martin, R., Morawska, L., Pope, C. A., Shin, H., Straif, K., Shaddick, G., Thomas, M., Dingenen, R. van, Donkelaar, A. van, Vos, T., Murray, C. J. L., and Forouzanfar, M. H.: Estimates and 25-year trends of the global burden of disease attributable to ambient air pollution: an analysis of data from the Global Burden of Diseases Study 2015, The Lancet, 389, $1907-$ 1918, https://doi.org/10.1016/S0140-6736(17)30505-6, 2017.

Colette, A., Andersson, C., Manders, A., Mar, K., Mircea, M., Pay, M.-T., Raffort, V., Tsyro, S., Cuvelier, C., Adani, M., Bessagnet, B., Bergström, R., Briganti, G., Butler, T., Cappelletti, A., Couvidat, F., D'Isidoro, M., Doumbia, T., Fagerli, H., Granier, C., Heyes, C., Klimont, Z., Ojha, N., Otero, N., Schaap, M., Sindelarova, K., Stegehuis, A. I., Roustan, Y., Vautard, R., van Meijgaard, E., Vivanco, M. G., and Wind, P.: EURODELTATrends, a multi-model experiment of air quality hindcast in Europe over 1990-2010, Geosci. Model Dev., 10, 3255-3276, https://doi.org/10.5194/gmd-10-3255-2017, 2017.

Colette, A., Granier, C., Hodnebrog, Ø., Jakobs, H., Maurizi, A., Nyiri, A., Bessagnet, B., D’Angiola, A., D’Isidoro, M., Gauss, M., Meleux, F., Memmesheimer, M., Mieville, A., Rouïl, L., Russo, F., Solberg, S., Stordal, F., and Tampieri, F.: Air quality trends in Europe over the past decade: a first multimodel assessment, Atmos. Chem. Phys., 11, 11657-11678, https://doi.org/10.5194/acp-11-11657-2011, 2011.

Couvidat, F. and Sartelet, K.: The Secondary Organic Aerosol Processor (SOAP v1.0) model: a unified model with different ranges of complexity based on the molecular surrogate approach, Geosci. Model Dev., 8, 1111-1138, https://doi.org/10.5194/gmd8-1111-2015, 2015.

Couvidat, F., Bessagnet, B., Garcia-Vivanco, M., Real, E., Menut, L., and Colette, A.: Development of an inorganic and organic aerosol model (CHIMERE 2017 $\beta$ v1.0): seasonal and spatial evaluation over Europe, Geosci. Model Dev., 11, 165-194, https://doi.org/10.5194/gmd-11-165-2018, 2018.

Couvidat, F., Debry, É., Sartelet, K., Seigneur, C.: A hydrophilic/hydrophobic organic $\left(\mathrm{H}^{2} \mathrm{O}\right)$ aerosol model: Develop- 
ment, evaluation and sensitivity analysis, J. Geophys. Res.Atmos., 117, D10304, https://doi.org/10.1029/2011JD017214, 2012.

Crippa, M., Canonaco, F., Lanz, V. A., Äijälä, M., Allan, J. D., Carbone, S., Capes, G., Ceburnis, D., Dall'Osto, M., Day, D. A., DeCarlo, P. F., Ehn, M., Eriksson, A., Freney, E., Hildebrandt Ruiz, L., Hillamo, R., Jimenez, J. L., Junninen, H., Kiendler-Scharr, A., Kortelainen, A.-M., Kulmala, M., Laaksonen, A., Mensah, A. A., Mohr, C., Nemitz, E., O’Dowd, C., Ovadnevaite, J., Pandis, S. N., Petäjä, T., Poulain, L., Saarikoski, S., Sellegri, K., Swietlicki, E., Tiitta, P., Worsnop, D. R., Baltensperger, U., and Prévôt, A. S. H.: Organic aerosol components derived from 25 AMS data sets across Europe using a consistent ME-2 based source apportionment approach, Atmos. Chem. Phys., 14, 61596176, https://doi.org/10.5194/acp-14-6159-2014, 2014

De Moore, W. B., Sandetr, S. P., Golden, D. M., Hampson, R. F., Kurylo, M. J., Howard, C. J., Ravishankara, A. R., Kolb, C. E., and Molina, M. J.: Chemical kinetics and photochimical data for use in stratospheric modelling evaluation, Jet Propulsion Laboratory, 1994.

Dee, D. P., Uppala, S. M., Simmons, A. J., Berrisford, P., Poli, P., Kobayashi, S., Andrae, U., Balmaseda, M. A., Balsamo, G., Bauer, P., Bechtold, P., Beljaars, A. C. M., van de Berg, I., Biblot, J., Bormann, N., Delsol, C., Dragani, R., Fuentes, M., Greer, A. J., Haimberger, L., Healy, S. B., Hersbach, H., Holm, E. V., Isaksen, L., Kallberg, P., Kohler, M., Matricardi, M., McNally, A. P., Mong-Sanz, B. M., Morcette, J.-J., Park, B.-K., Peubey, C., de Rosnay, P., Tavolato, C., Thepaut, J. N., and Vitart, F.: The ERAInterim reanalysis: Configuration and performance of the data assimilation system, Q. J. Roy. Meteorol. Soc., 137, 553-597, https://doi.org/10.1002/qj.828, 2011.

Denier van der Gon, H. A. C., Bergström, R., Fountoukis, C., Johansson, C., Pandis, S. N., Simpson, D., and Visschedijk, A. J. H.: Particulate emissions from residential wood combustion in Europe - revised estimates and an evaluation, Atmos. Chem. Phys., 15, 6503-6519, https://doi.org/10.5194/acp15-6503-2015, 2015.

Derognat, C., Beekmann, M., Baeumle, M., Martin, D., and Schmidt, H.: Effect of biogenic volatile organic compound emissions on tropospheric chemistry during the Atmospheric Pollution Over the Paris Area (ESQUIF) campaign in the Ile-de-France region, J. Geophys. Res., 108, 8560, https://doi.org/10.1029/2001JD001421, 2003.

Donahue, N. M., Epstein, S. A., Pandis, S. N., and Robinson, A. L.: A two-dimensional volatility basis set: 1. organic-aerosol mixing thermodynamics, Atmos. Chem. Phys., 11, 3303-3318, https://doi.org/10.5194/acp-11-3303-2011, 2011.

Donahue, N. M., Kroll, J. H., Pandis, S. N., and Robinson, A. L.: A two-dimensional volatility basis set - Part 2: Diagnostics of organic-aerosol evolution, Atmos. Chem. Phys., 12, 615-634, https://doi.org/10.5194/acp-12-615-2012, 2012.

EEA EEA Report, No 4/2012, Air quality in Europe - 2010 Report, https://doi.org/10.2800/55823, 2012.

EMEP: Data Report 2010 Acidifying and eutrophying compounds and particulate matter, EMEP/CCC-Report 1/2012, available at: https://www.nilu.no/projects/ccc/reports/cccr1-2012.pdf (last access: 14 November 2019), 2012

Fagerli, H. and Aas, W.: Trends of nitrogen in air and precipitation: Model results and observations at EMEP sites in Europe, 1980-2003, Environ. Pollut., 154, 448-461, https://doi.org/10.1016/j.envpol.2008.01.024, 2008.

Fountoukis, C. and Nenes, A.: ISORROPIA II: a computationally efficient thermodynamic equilibrium model for $\mathrm{K}^{+}-\mathrm{Ca}^{2+}-\mathrm{Mg}_{2+}-\mathrm{NH}_{4+}-\mathrm{Na}^{+}-\mathrm{SO}_{4}^{2-}-\mathrm{NO}_{3}^{-}-\mathrm{Cl}^{-}-\mathrm{H}_{2} \mathrm{O}$ aerosols, Atmos. Chem. Phys., 7, 4639-4659, https://doi.org/10.5194/acp-7-4639-2007, 2007.

Grell, G. A., Peckham, S. E., Schmitz, R., McKeen, S. A., Frost, G., Skamarock, W. C., and Eder, B.: Fully coupled "online" chemistry within the WRF model, Atmos. Environ., 39, 6957-6975, https://doi.org/10.1016/j.atmosenv.2005.04.027, 2005.

Guenther, A., Karl, T., Harley, P., Wiedinmyer, C., Palmer, P. I., and Geron, C.: Estimates of global terrestrial isoprene emissions using MEGAN (Model of Emissions of Gases and Aerosols from Nature), Atmos. Chem. Phys., 6, 3181-3210, https://doi.org/10.5194/acp-6-3181-2006, 2006.

Guenther, A. B., Jiang, X., Heald, C. L., Sakulyanontvittaya, T., Duhl, T., Emmons, L. K., and Wang, X.: The Model of Emissions of Gases and Aerosols from Nature version 2.1 (MEGAN2.1): an extended and updated framework for modeling biogenic emissions, Geosci. Model Dev., 5, 1471-1492, https://doi.org/10.5194/gmd-5-1471-2012, 2012.

Guenther, A. B., Zimmerman, P. R., Harley, P. C., Monson, R. K., and Fall, R.: Isoprene and monoterpene emission rate variability: Model evaluations and sensitivity analyses, J. Geophys. Res., 98, 12609, https://doi.org/10.1029/93JD00527, 1993.

Hendriks, C., Kranenburg, R., Kuenen, J. J. P., Van den Bril, B., Verguts, V., and Schaap, M.: Ammonia emission time profiles based on manure transport data improve ammonia modelling across north western Europe, Atmos. Environ., 131, 8396, https://doi.org/10.1016/j.atmosenv.2016.01.043, 2016.

Huang, G., Brook, R., Crippa, M., Janssens-Maenhout, G., Schieberle, C., Dore, C., Guizzardi, D., Muntean, M., Schaaf, E., and Friedrich, R.: Speciation of anthropogenic emissions of non-methane volatile organic compounds: a global gridded data set for 1970-2012, Atmos. Chem. Phys., 17, 7683-7701, https://doi.org/10.5194/acp-17-7683-2017, 2017.

Huang, R.-J., Zhang, Y., Bozzetti, C., Ho, K.-F., Cao, J.-J., Han, Y., Daellenbach, K. R., Slowik, J. G., Platt, S. M., Canonaco, F., Zotter, P., Wolf, R., Pieber, S. M., Bruns, E. A., Crippa, M., Ciarelli, G., Piazzalunga, A., Schwikowski, M., Abbaszade, G., SchnelleKreis, J., Zimmermann, R., An, Z., Szidat, S., Baltensperger, U., Haddad, I. E., and Prévôt, A. S. H.: High secondary aerosol contribution to particulate pollution during haze events in China, Nature, 514, 218-222, https://doi.org/10.1038/nature13774, 2014.

IEA: Energy Statistics of OECD Countries, International Energy Agency Paris, France, 2012.

Jimenez, J. L., Canagaratna, M. R., Donahue, N. M., Prevot, A. S. H., Zhang, Q., Kroll, J. H., DeCarlo, P. F., Allan, J. D., Coe, H., Ng, N. L., Aiken, A. C., Docherty, K. S., Ulbrich, I. M., Grieshop, A. P., Robinson, A. L., Duplissy, J., Smith, J. D., Wilson, K. R., Lanz, V. A., Hueglin, C., Sun, Y. L., Tian, J., Laaksonen, A., Raatikainen, T., Rautiainen, J., Vaattovaara, P., Ehn, M., Kulmala, M., Tomlinson, J. M., Collins, D. R., Cubison, M. J., E, Dunlea, J., Huffman, J. A., Onasch, T. B., Alfarra, M. R., Williams, P. I., Bower, K., Kondo, Y., Schneider, J., Drewnick, F., Borrmann, S., Weimer, S., Demerjian, K., Salcedo, D., Cottrell, L., Griffin, R., Takami, A., Miyoshi, T., Hatakeyama, S., Shimono, A., Sun, J.Y., Zhang, Y. M., Dzepina, K., Kimmel, 
J. R., Sueper, D., Jayne, J. T., Herndon, S. C., Trimborn, A. M., Williams, L. R., Wood, E. C., Middlebrook, A. M., Kolb, C. E., Baltensperger, U., and Worsnop, D. R.: Evolution of Organic Aerosols in the Atmosphere, Science, 326, 1525-1529, https://doi.org/10.1126/science.1180353, 2009.

Kendall, M. G.: Rank correlation methods, Rank correlation methods, Griffin, Oxford, England, 1948.

Koeble, R. and Seufert, G.: Novel Maps for Forest Tree Species in Europe, A Changing Atmosphere, 8th European Symposium on the Physico-Chemical Behaviour of Atmospheric Pollutants, Torino, Italy, 17-20 September, 2001.

Lachatre, M., Fortems-Cheiney, A., Foret, G., Siour, G., Dufour, G., Clarisse, L., Clerbaux, C., Coheur, P.-F., Van Damme, M., and Beekmann, M.: The unintended consequence of $\mathrm{SO}_{2}$ and $\mathrm{NO}_{2}$ regulations over China: increase of ammonia levels and impact on $\mathrm{PM}_{2.5}$ concentrations, Atmos. Chem. Phys., 19, 6701-6716, https://doi.org/10.5194/acp-19-6701-2019, 2019.

Langner, J., Bergström, R., and Pleijel, K.: European scale modeling of sulphur, oxidized nitrogen and photochemical oxidants, Model development and evaluation for the 1994 growing season, SMHI report, 1998.

Mailler, S., Menut, L., Khvorostyanov, D., Valari, M., Couvidat, F., Siour, G., Turquety, S., Briant, R., Tuccella, P., Bessagnet, B., Colette, A., Létinois, L., Markakis, K., and Meleux, F.: CHIMERE-2017: from urban to hemispheric chemistrytransport modeling, Geosci. Model Dev., 10, 2397-2423, https://doi.org/10.5194/gmd-10-2397-2017, 2017.

Mallet, V., Quélo, D., Sportisse, B., Ahmed de Biasi, M., Debry, É., Korsakissok, I., Wu, L., Roustan, Y., Sartelet, K., Tombette, M., and Foudhil, H.: Technical Note: The air quality modeling system Polyphemus, Atmos. Chem. Phys., 7, 5479-5487, https://doi.org/10.5194/acp-7-5479-2007, 2007.

Manders, A. M. M., Builtjes, P. J. H., Curier, L., Denier van der Gon, H. A. C., Hendriks, C., Jonkers, S., Kranenburg, R., Kuenen, J. J. P., Segers, A. J., Timmermans, R. M. A., Visschedijk, A. J. H., Wichink Kruit, R. J., van Pul, W. A. J., Sauter, F. J., van der Swaluw, E., Swart, D. P. J., Douros, J., Eskes, H., van Meijgaard, E., van Ulft, B., van Velthoven, P., Banzhaf, S., Mues, A. C., Stern, R., Fu, G., Lu, S., Heemink, A., van Velzen, N., and Schaap, M.: Curriculum vitae of the LOTOS-EUROS (v2.0) chemistry transport model, Geosci. Model Dev., 10, 4145-4173, https://doi.org/10.5194/gmd-10-4145-2017, 2017.

Mann, H. B.: Nonparametric Tests Against Trend, Econometrica, 13, 245-259, https://doi.org/10.2307/1907187, 1945.

Mar, K. A., Ojha, N., Pozzer, A., and Butler, T. M.: Ozone air quality simulations with WRF-Chem (v3.5.1) over Europe: model evaluation and chemical mechanism comparison, Geosci. Model Dev., 9, 3699-3728, https://doi.org/10.5194/gmd-9-3699-2016, 2016.

Menut, L., Bessagnet, B., Khvorostyanov, D., Beekmann, M., Blond, N., Colette, A., Coll, I., Curci, G., Foret, G., Hodzic, A., Mailler, S., Meleux, F., Monge, J.-L., Pison, I., Siour, G., Turquety, S., Valari, M., Vautard, R., and Vivanco, M. G.: CHIMERE 2013: a model for regional atmospheric composition modelling, Geosci. Model Dev., 6, 981-1028, https://doi.org/10.5194/gmd-6-981-2013, 2013.

Mircea, M.: Impact of Grid Resolution on Aerosol Predictions: A Case Study over Italy, Aerosol Air Qual. Res., 16, 1253-1267, https://doi.org/10.4209/aaqr.2015.02.0058, 2016.
Mozurkewich, M.: The dissociation constant of ammonium nitrate and its dependence on temperature, relative humidity and particle size, Atmos. Environ., 27, 261-270, https://doi.org/10.1016/0960-1686(93)90356-4, 1993.

Nenes, A., Pilinis, C., and Pandis, S. N.: ISORROPIA: A new thermodynamic equilibrium model for multiphase multicomponent inorganic aerosols, Aquat. Geochem., 4, 123-152, 1998.

Nenes, A., Pandis, S. N., and Pilinis, C.: Continued development and testing of a new thermodynamic aerosol module for urban and regional air quality models, Atmos. Environ., 33, 15531560, https://doi.org/10.1016/S1352-2310(98)00352-5, 1999.

Oikonomakis, E., Aksoyoglu, S., Wild, M., Ciarelli, G., Baltensperger, U., and Prévôt, A. S. H.: Solar "brightening" impact on summer surface ozone between 1990 and 2010 in Europe - a model sensitivity study of the influence of the aerosolradiation interactions, Atmos. Chem. Phys., 18, 9741-9765, https://doi.org/10.5194/acp-18-9741-2018, 2018.

Paatero, P.: The Multilinear Engine - A Table-Driven, Least Squares Program for Solving Multilinear Problems, Including the n-Way Parallel Factor Analysis Model, J. Comput. Graph. Stat., 8, 854-888, https://doi.org/10.1080/10618600.1999.10474853, 1999.

Pope, C. A. and Dockery, D. W.: Health Effects of Fine Particulate Air Pollution: Lines that Connect, J. Air Waste Manag. Assoc., 56, 709-742, https://doi.org/10.1080/10473289.2006.10464485, 2006.

Reed, C., Evans, M. J., Di Carlo, P., Lee, J. D., and Carpenter, L. J.: Interferences in photolytic NO2 measurements: explanation for an apparent missing oxidant?, Atmos. Chem. Phys., 16, 47074724, https://doi.org/10.5194/acp-16-4707-2016, 2016.

Robertson, L., Langner, J., and Engardt, M.: An Eulerian Limited-Area Atmospheric Transport Model, J. Appl. Meteorol., 38, 190-210, https://doi.org/10.1175/15200450(1999)038<0190:AELAAT>2.0.CO;2, 1999.

Sartelet, K. N., Couvidat, F., Seigneur, C., and Roustan, Y.: Impact of biogenic emissions on air quality over Europe and North America, Atmos. Environ., 53, 131-141, https://doi.org/10.1016/j.atmosenv.2011.10.046, 2012.

Schaap, M., Timmermans, R. M. A., Roemer, M., Boersen, G. A. C., Builtjes, P. J. H., Sauter, F. J., Velders, G. J. M., and Beck, J. P.: The LOTOS EUROS model: description, validation and latest developments, Int. J. Environ. Pollut., 32, 270-290, https://doi.org/10.1504/IJEP.2008.017106, 2008.

Schaap, M., Manders, A. M. M., Hendriks, E., Cnossen, J. M., Segers, A. J., Denier van der Gon, H. A. C., Jozwicka, M., Sauter, F. J., Velders, G. J. M., and Beck, J. P.: Regional Modelling of Particulate Matter for the Netherlands, PBL report 500099008, 2009.

Schell, M., Ackermann, I. J., Hass, H., Binkowski, F. S., and Ebel, A.: Modeling the formation of secondary organic aerosol within a comprehensive air quality model system, J. Geophys. Res.-Atmos., 106, 28275-28293, https://doi.org/10.1029/2001JD000384, 2001.

Seinfeld, J. H. and Pandis, S. N.: Atmospheric Chemistry and Physics: From Air Pollution to Climate Change, Wiley, 2012.

Sen, P. K.: Estimates of the Regression Coefficient Based on Kendall's Tau, J. Am. Stat. Assoc., 63, 1379-1389, https://doi.org/10.1080/01621459.1968.10480934, 1968. 
Simpson, D., Andersson, C., Christensen, J. H., Engardt, M., Geels, C., Nyiri, A., Posch, M., Soares, J., Sofiev, M., Wind, P., and Langner, J.: Impacts of climate and emission changes on nitrogen deposition in Europe: a multi-model study, Atmos. Chem. Phys., 14, 6995-7017, https://doi.org/10.5194/acp14-6995-2014, 2014.

Simpson, D., Benedictow, A., Berge, H., Bergström, R., Emberson, L. D., Fagerli, H., Flechard, C. R., Hayman, G. D., Gauss, M., Jonson, J. E., Jenkin, M. E., Nyíri, A., Richter, C., Semeena, V. S., Tsyro, S., Tuovinen, J.-P., Valdebenito, Á., and Wind, P.: The EMEP MSC-W chemical transport model - technical description, Atmos. Chem. Phys., 12, 7825-7865, https://doi.org/10.5194/acp-12-7825-2012, 2012.

Skamarock, W., Klemp, J., Dudhia, J., Gill, D., Barker, D., Wang, W., Huang, X. Y., and Duda, M.: A Description of the Advanced Research WRF Version 3, UCAR/NCAR, https://doi.org/10.5065/D68S4MVH, 2008.

Stegehuis, A. I., Vautard, R., Ciais, P., Teuling, A. J., Miralles, D. G., and Wild, M.: An observation-constrained multi-physics WRF ensemble for simulating European mega heat waves, Geosci. Model Dev., 8, 2285-2298, https://doi.org/10.5194/gmd8-2285-2015, 2015.

Terrenoire, E., Bessagnet, B., Rouïl, L., Tognet, F., Pirovano, G., Létinois, L., Beauchamp, M., Colette, A., Thunis, P., Amann, M., and Menut, L.: High-resolution air quality simulation over Europe with the chemistry transport model CHIMERE, Geosci. Model Dev., 8, 21-42, https://doi.org/10.5194/gmd-8-21-2015, 2015.

Theobald, M. R., Vivanco, M. G., Aas, W., Andersson, C., Ciarelli, G., Couvidat, F., Cuvelier, K., Manders, A., Mircea, M., Pay, M.T., Tsyro, S., Adani, M., Bergström, R., Bessagnet, B., Briganti, G., Cappelletti, A., D’Isidoro, M., Fagerli, H., Mar, K., Otero, N., Raffort, V., Roustan, Y., Schaap, M., Wind, P., and Colette, A.: An evaluation of European nitrogen and sulfur wet deposition and their trends estimated by six chemistry transport models for the period 1990-2010, Atmos. Chem. Phys., 19, 379-405, https://doi.org/10.5194/acp-19-379-2019, 2019.

Tørseth, K., Aas, W., Breivik, K., Fjæraa, A. M., Fiebig, M., Hjellbrekke, A. G., Lund Myhre, C., Solberg, S., and Yttri, K. E.: Introduction to the European Monitoring and Evaluation Programme (EMEP) and observed atmospheric composition change during 1972-2009, Atmos. Chem. Phys., 12, 5447-5481, https://doi.org/10.5194/acp-12-5447-2012, 2012.

Tsigaridis, K., Daskalakis, N., Kanakidou, M., Adams, P. J., Artaxo, P., Bahadur, R., Balkanski, Y., Bauer, S. E., Bellouin, N., Benedetti, A., Bergman, T., Berntsen, T. K., Beukes, J. P., Bian, H., Carslaw, K. S., Chin, M., Curci, G., Diehl, T., Easter, R. C., Ghan, S. J., Gong, S. L., Hodzic, A., Hoyle, C. R., Iversen, T., Jathar, S., Jimenez, J. L., Kaiser, J. W., Kirkevåg, A., Koch, D., Kokkola, H., Lee, Y. H., Lin, G., Liu, X., Luo, G., Ma, X., Mann, G. W., Mihalopoulos, N., Morcrette, J.-J., Müller, J.-F., Myhre, G., Myriokefalitakis, S., Ng, N. L., O’Donnell, D., Penner, J. E., Pozzoli, L., Pringle, K. J., Russell, L. M., Schulz, M., Sciare, J., Seland, Ø., Shindell, D. T., Sillman, S., Skeie, R. B., Spracklen, D., Stavrakou, T., Steenrod, S. D., Takemura, T., Tiitta, P., Tilmes, S., Tost, H., van Noije, T., van Zyl, P. G., von Salzen, K., Yu, F., Wang, Z., Wang, Z., Zaveri, R. A., Zhang, H., Zhang, K., Zhang, Q., and Zhang, X.: The AeroCom evaluation and intercomparison of organic aerosol in global models, Atmos.
Chem. Phys., 14, 10845-10895, https://doi.org/10.5194/acp-1410845-2014, 2014.

Tsimpidi, A. P., Karydis, V. A., and Pandis, S. N.: Response of Inorganic Fine Particulate Matter to Emission Changes of Sulfur Dioxide and Ammonia: The Eastern United States as a Case Study, J. Air Waste Manag. Assoc., 57, 1489-1498, https://doi.org/10.3155/1047-3289.57.12.1489, 2007.

Tsimpidi, A. P., Karydis, V. A., Pandis, S. N., and Lelieveld, J.: Global combustion sources of organic aerosols: model comparison with 84 AMS factor-analysis data sets, Atmos. Chem. Phys., 16, 8939-8962, https://doi.org/10.5194/acp-168939-2016, 2016.

UNECE: Protocol to the 1979 Convention on Long-Range Tansboundary Air Pollution to abate acidification, eutrophication and ground-level ozone, United Nations Economic Commission for Europe, 1999.

UNECE LRTAP: Towards Cleaner Air, Scientific Assessment Report 2016, EMEP Steering Body and Working Group on Effects of the Convention on Long-Range Transboundary Air Pollution, Oslo, $\mathrm{xx}+50$ pp., 2016.

van Loon, M., Vautard, R., Schaap, M., Bergström, R., Bessagnet, B., Brandt, J., Builtjes, P. J. H., Christensen, J. H., Cuvelier, C., Graff, A., Jonson, J. E., Krol, M., Langner, J., Roberts, P., Rouil, L., Stern, R., Tarrasón, L., Thunis, P., Vignati, E., White, L., and Wind, P.: Evaluation of long-term ozone simulations from seven regional air quality models and their ensemble, Atmos. Environ., 41, 2083-2097, https://doi.org/10.1016/j.atmosenv.2006.10.073, 2007.

WHO: Health risks of air pollution in Europe - HRAPIE - Summary of recommendations for question D5 on "Identification of concentration-response functions" for cost-effectiveness analysis, World Health Organisation, 2013.

Wild, M.: Global dimming and brightening: A review, 114, D00D16, https://doi.org/10.1029/2008JD011470, 2009. 